\title{
Aging and Charge Compensation Effects of the Rechargeable Aqueous Zinc/Copper Hexacyanoferrate Battery Elucidated Using In Situ X-ray Techniques
}

\author{
Mikaela Görlin,* Dickson O. Ojwang, Ming-Tao Lee, Viktor Renman, Cheuk-Wai Tai, \\ and Mario Valvo*
}

Cite This: ACS Appl. Mater. Interfaces 2021, 13, 59962-59974

Read Online

ACCESS | Lلll Metrics \& More | 回 Article Recommendations

Supporting Information

ABSTRACT: The zinc/copper hexacyanoferrate $(\mathrm{Zn} / \mathrm{CuHCF})$ cell has gained attention as an aqueous rechargeable zinc-ion battery (ZIB) owing to its open framework, excellent rate capability, and high safety. However, both the $\mathrm{Zn}$ anode and the CuHCF cathode show unavoidable signs of aging during cycling, though the underlying mechanisms have remained somewhat ambiguous. Here, we present an in-depth study of the CuHCF cathode by employing various $\mathrm{X}$-ray spectroscopic techniques. This allows us to distinguish between structure-related aging effects and charge compensation processes associated with electroactive metal centers upon $\mathrm{Zn}^{2+}$ ion insertion/deinsertion. By combining high-angle annular dark-field-scanning electron transmission microscopy, X-ray absorption spectroscopy (XAS), X-ray photoelectron spectroscopy,

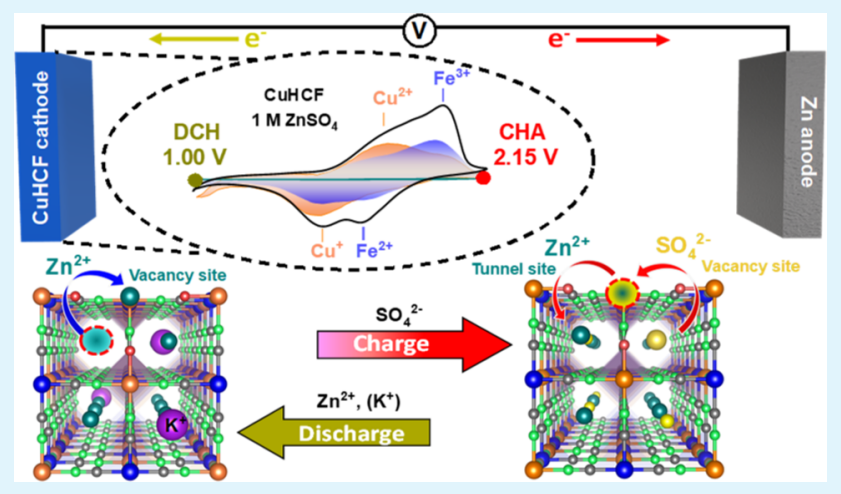
and elemental analysis, we reconstruct the picture of both the bulk and the surface. First, we identify a set of previously debated X-ray diffraction peaks appearing at early stages of cycling (below 200 cycles) in CuHCF. Our data suggest that these peaks are unrelated to hypothetical $\mathrm{Zn}_{x} \mathrm{Cu}_{1-x} \mathrm{HCF}$ phases or to oxidic phases, but are caused by partial intercalation of $\mathrm{ZnSO}_{4}$ into graphitic carbon. We further conclude that $\mathrm{Cu}$ is the unstable species during aging, whose dissolution is significant at the surface of the CuHCF particles. This triggers $\mathrm{Zn}^{2+}$ ions to enter newly formed Cu vacancies, in addition to native $\mathrm{Fe}$ vacancies already present in the bulk, which causes a reduction of nearby metal sites. This is distinct from the charge compensation process where both the $\mathrm{Cu}^{2+} / \mathrm{Cu}^{+}$and $\mathrm{Fe}^{3+} / \mathrm{Fe}^{2+}$ redox couples participate throughout the bulk. By tracking the K-edge fluorescence using operando XAS coupled with cyclic voltammetry, we successfully link the aging effect to the activation of the $\mathrm{Fe}^{3+} / \mathrm{Fe}^{2+}$ redox couple as a consequence of $\mathrm{Cu}$ dissolution. This explains the progressive increase in the voltage of the charge/ discharge plateaus upon repeated cycling. We also find that $\mathrm{SO}_{4}{ }^{2-}$ anions reversibly insert into CuHCF during charge. Our work clarifies several intriguing structural and redox-mediated aging mechanisms in the CuHCF cathode and pinpoints parameters that correlate with the performance, which will hold importance for the development of future Prussian blue analogue-type cathodes for aqueous rechargeable ZIBs.

KEYWORDS: aqueous rechargeable zinc-ion batteries, zinc copper hexacyanoferrate, Prussian blue analogues, aging effects, charge compensation process, in situ X-ray absorption spectroscopy, X-ray photoelectron spectroscopy, X-ray diffraction

\section{INTRODUCTION}

The use of renewable energies is imperative to lower the greenhouse gas emissions and progressively develop a society free of fossil fuel dependence. ${ }^{1}$ Storage of electricity produced via renewable energies is a critical link toward greener energy production and distribution worldwide. Harnessing electricity generated by renewable sources requires the development of versatile and robust energy storage systems (ESSs). Attaining both low-cost, minimum environmental footprint, and high safety is important to facilitate the use of these systems on a larger scale. ${ }^{2}$ Rechargeable batteries are the fastest-growing EESs owing to their efficient use in electric vehicles (EVs), where Li-ion batteries (LIBs) currently is the dominating technology. ${ }^{3-5}$ However, less attention has been paid to "greener" EES options for stationary storage applications. Rechargeable aqueous zinc-ion batteries (ZIBs) are considered one of the most promising upcoming technologies for

Received: October 5, 2021

Accepted: November 24, 2021

Published: December 8, 2021 

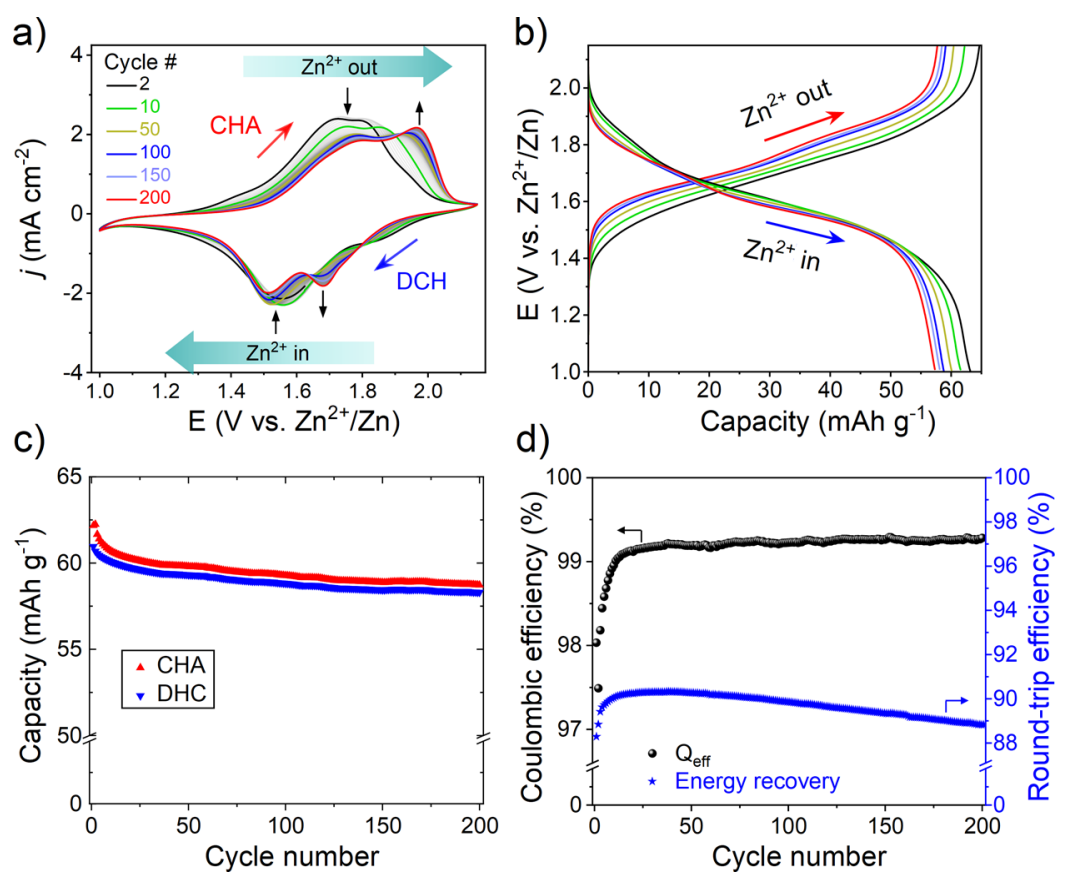

Figure 1. Voltammetric and galvanostatic charge/discharge profiles of the $\mathrm{Zn} / \mathrm{CuHCF}$ cell in $1 \mathrm{M} \mathrm{ZnSO}_{4}$. (a) $\mathrm{CV}$ curves at $2.5 \mathrm{mV} \mathrm{s}{ }^{-1}$ showing the first 200 cycles of the $\mathrm{Zn} / \mathrm{CuHCF}$ cell. (b) Galvanostatic charge/discharge voltage profiles obtained at around 8C rate. (c) Evolution of the charge/ discharge capacities in each cycle obtained from galvanostatic cycling at around 8C rate. (d) Coulombic efficiency (left) and round-trip efficiency (right). Note the gradual increase of the voltage profiles for the charge curves in (b) with the development of a feature resembling a two-step voltage plateau with increasing cycle number. The first cycle has been omitted for clarity. All experiments were performed between 1.00 and $2.15 \mathrm{~V}$ vs $\mathrm{Zn}^{2+} / \mathrm{Zn}$. The red arrows in $(\mathrm{a}-\mathrm{b})$ indicate the charge process (CHA), and the blue arrows indicate the discharge process (DCH).

stationary applications such as grid storage and uninterruptible power supply applications due to their nontoxicity, low price, high safety (i.e., nonflammability), and abundance of the zinc metal. $^{6-11}$

Despite the relatively low energy density and short cycle life compared to that of, for example, LIBs, the zinc metal has a high gravimetric capacity of $820 \mathrm{mAh} \mathrm{g}^{-1}$ and a low reduction potential $\left(-0.78 \mathrm{~V}\right.$ vs standard hydrogen electrode). ${ }^{12}$ This allows for high operational voltages within the electrochemical stability window of water.

Prussian blue analogues (PBAs) have recently gained interest as cathode materials due to their open framework, which allows for reversible $\mathrm{Zn}^{2+}$ ion insertion/deinsertion, easy synthesis routes, and compatibility with a variety of metal cations. $^{13-22}$ These open framework compounds open up for the use of electrolytes with a mild $\mathrm{pH}$, thus avoiding strongly acidic or alkaline conditions.

Here, we investigate the zinc/copper hexacyanoferrate $(\mathrm{Zn} /$ CuHCF) system, a PBA suggested as a possible ZIB cathode material in 2015 by Trócoli and La Mantia ${ }^{18}$ and Jia et al., ${ }^{17}$ being known at the time to host other cations. ${ }^{19,23-25} \mathrm{CuHCF}$ has a typical gravimetric capacity of around $60 \mathrm{mAh} \mathrm{g}^{-1}$, a high operating potential of $\sim 1.7 \mathrm{~V}$, and negligible structural changes and volume expansion during $\mathrm{Zn}^{2+}$ ion insertion (i.e., near-zero strain). This allows for fast ion insertion and makes this type of ZIBs more suitable for high power applications compared to, for example, manganese dioxide batteries $\left(\mathrm{Zn} / \mathrm{MnO}_{2}\right)$, which exhibit generally higher gravimetric capacities instead.

PBAs are structural analogues with perovskites, where bridged cyanide ligands ( $\mathrm{CN}$ ) form a three-dimensional network in an octahedral arrangement around the central transition metal atom. The generic formula can be written as $\mathrm{A}_{x} \mathrm{M}\left[\mathrm{M}^{\prime}(\mathrm{CN})_{6}\right]_{1-y} \cdot \square_{y} \cdot n \mathrm{H}_{2} \mathrm{O}(0<x<1, y<1)$, where in
CuHCF, $\mathrm{A}=\mathrm{Zn}^{2+}$ or zeolitic water, $\mathrm{M}=\mathrm{Cu}^{2+}, \mathrm{M}^{\prime}=\mathrm{Fe}^{3+}$, and $\square=\mathrm{Fe}(\mathrm{CN})_{6}$ vacancy. ${ }^{13,26}$ The outer $\mathrm{M}$ site $\left(\mathrm{Cu}^{2+}\right)$ is coordinated to the $\mathrm{N}$-end, while the inner $\mathrm{M}^{\prime}$ site $\left(\mathrm{Fe}^{3+}\right)$ is coordinated to the C-end. In our CuHCF material, one-third of the $\mathrm{Fe}(\mathrm{CN})_{6}$ vacancies in the native structure are attributed to the $\mathrm{Cu} / \mathrm{Fe}$ ratio of $\sim 1.5$, which typically are occupied by coordinating water molecules. ${ }^{13,27}$

Despite the relatively short cycle life and low energy density that comes with $\mathrm{CuHCF}$ and PBA-type cathodes in rechargeable aqueous systems, several advantageous features such as environmental compatibility, low cost, safety, moderate capacity, and fast ion insertion still motivate the use of these compounds in future ZIBs. The development of aqueous PBAbased ZIBs is still at its infant stage, and despite considerable advances in the recent past, there are various processes related to aging and capacity fade that are still not well-understood. $^{28-32}$ This is what motivates this study.

Dissolution of metal species from CuHCF (especially $\mathrm{Cu}$ ) has been observed during cycling, although the extent of this is still debated. Furthermore, $\mathrm{Zn}^{2+}$ ions have been reported to become irreversibly trapped in $\mathrm{CuHCF}$, which is proposed to trigger phase segregation and formation of new nonstoichiometric $\mathrm{Zn}$-rich phases $\left.\left(\mathrm{Zn}_{x} \mathrm{Cu}_{1-x} \mathrm{CuHCF}\right)\right)^{28,29,32,33}$ These phases are thought to be responsible for new X-ray diffraction (XRD) peaks that appear with cycling, although some of the peaks have not yet been conclusively identified. ${ }^{28,30,34}$ The $\mathrm{Zn}^{2+}$ trapping and formation of new $\mathrm{Zn}$-rich phases have been proposed to be responsible for shifting the $\mathrm{Zn}^{+}$ion insertion (or the charge/discharge voltage plateaus) to higher potentials. $^{29,32}$ Nevertheless, uncertainties still remain around both the mechanism of $\mathrm{Cu}$ dissolution and the origin of these new diffraction peaks, especially at early stages of cycling. ${ }^{11} \mathrm{~A}$ new charge compensation mechanism based on operando 
XRD was earlier put forward by Renman et al., ${ }^{31}$ where trapped $\mathrm{Zn}^{2+}$ ions were proposed to swap between interstitial tunnel sites (i.e., Wyckoff notation as $8 \mathrm{c}$ ) and $\mathrm{Fe}(\mathrm{CN})_{6}$ vacancies (Wyckoff notation as $4 \mathrm{a}$ ), thus explaining why $\mathrm{Zn}^{2+}$ ions do not exit CuHCF during charge.

During monovalent cation insertion, typically only one metal center is electroactive in PBAs (i.e., $\mathrm{Fe}^{3+} / \mathrm{Fe}^{2+}$ ); however, during divalent cation insertion $\left(\mathrm{Zn}^{2+}\right)$, the second metal center may also become electroactive (i.e., $\left.\mathrm{Cu}^{2+} / \mathrm{Cu}^{+}\right){ }^{16}$ Currently, very few studies exist that metodically probe redoxactive metal centers in the aqueous $\mathrm{Zn} / \mathrm{CuHCF}$ cell. To the best of our knowledge, we are only aware of the investigation by $\mathrm{Lim}$ et al., ${ }^{30}$ where electron energy loss spectroscopy revealed the participation of both $\mathrm{Cu}^{2+} / \mathrm{Cu}^{+}$and $\mathrm{Fe}^{3+} / \mathrm{Fe}^{2+}$ redox couples during $\mathrm{Zn}^{2+}$ insertion. Otherwise, both electroactive $\mathrm{Cu}$ and $\mathrm{Fe}$ centers have been reported during $\mathrm{Li}^{+}$ion insertion $^{35,36}$ and $\mathrm{K}^{+}$ion insertion in similar $\mathrm{CuHCF}$ materials. $^{37}$

Here, we employ various in situ X-ray spectroscopic techniques to clarify the aging, charge compensation, and degradation processes in the aqueous $\mathrm{Zn} / \mathrm{CuHCF}$ cell up to 200 cycles. We employ a combination of X-ray absorption spectroscopy (XAS), X-ray photoelectron spectroscopy (XPS), $\mathrm{X}$-ray diffraction (XRD), aberration-corrected high-angle annular dark-field scanning transmission electron microscopy (HAADF-STEM), and elemental analysis. In short, we resolve the electroactivity related to both the $\mathrm{Cu}^{2+} / \mathrm{Cu}^{+}$and $\mathrm{Fe}^{3+} / \mathrm{Fe}^{2+}$ redox couples during $\mathrm{Zn}^{2+}$ insertion, which we link to the redox peaks in the cyclic voltammetric profile in a potentiodynamic fashion. We further reveal new information on the extent and location of $\mathrm{Cu}$ dissolution, we relate previously debated XRD peaks to graphitic carbon, and we make new relevant observations of $\mathrm{SO}_{4}{ }^{2-}$ anions participating in the charge compensation process. Our findings and discussion provide an in-depth understanding of the limiting factors for this intriguing aqueous $\mathrm{Zn} / \mathrm{CuHCF}$ system. The detailed analyses, combined with our tailored X-ray approach, pave the way toward the development of aimed methodologies for accurate insights into the key components of these ZIBs, thus enabling future improvements of this challenging rechargeable Zn-ion technology.

\section{RESULTS AND DISCUSSION}

2.1. Electrochemical Behavior of the Aqueous $\mathrm{Zn} /$ CuHCF Cell. The electrochemical characteristics of the aqueous $\mathrm{Zn} / \mathrm{CuHCF}$ cell are shown in Figure 1a,d. A depotassiated form of $\mathrm{CuHCF}$ was employed as the cathode $\left(\mathrm{K}_{2 x / 3} \mathrm{Cu}^{2+}\left[\mathrm{Fe}^{3+}(\mathrm{CN})_{6}\right]_{2 / 3} \cdot 3.3 \mathrm{H}_{2} \mathrm{O}, x \approx 0\right)$, and metallic $\mathrm{Zn}$ as the anode. The cathode is made up of $75 \mathrm{wt} \% \mathrm{CuHCF}, 15 \mathrm{wt}$ $\%$ polyvinyl alcohol (PVA) binder, and $10 \mathrm{wt} \%$ carbon black (CB). The experimental $\mathrm{Cu} / \mathrm{Fe}$ ratio is $\sim 1.5$ in the pristine CuHCF material, which was determined from inductively coupled plasma-optical emission spectroscopy (ICP-OES). This ratio is known to result in $\sim 1 / 3$ of $\mathrm{Fe}(\mathrm{CN})_{6}$ vacancies in the native crystal structure. The water content was estimated using thermogravimetric analysis, which further allowed for the determination of the molecular weight $\left(267.07 \mathrm{~g} \mathrm{~mol}^{-1}\right.$ ) (see Supporting Information Figure S1).

Cyclic voltammetry $(\mathrm{CV})$ of the $\mathrm{Zn} / \mathrm{CuHCF}$ cell at a sweep rate of $2.5 \mathrm{mV} \mathrm{s}^{-1}$ (corresponding to $\sim 8 \mathrm{C}$ ) in $1 \mathrm{M} \mathrm{ZnSO}_{4}$ reveals a typical double-peak feature during discharge/charge as $\mathrm{Zn}^{2+}$ ions insert/deinsert into the CuHCF framework (Figure 1a), in accordance with previous studies. ${ }^{29,32}$ On the anodic sweep (i.e., during charge $/ \mathrm{Zn}^{2+}$ ion "deinsertion" or swapping to $8 \mathrm{c}$ interstitial tunnel sites), there are two redox features at $\sim 1.7 \mathrm{~V}$ and at $\sim 1.8 \mathrm{~V}$ versus $\mathrm{Zn}^{2+} / \mathrm{Zn}$ (Figure 1a). A weak prefeature is sometimes visible at $\sim 1.4 \mathrm{~V}$; however, this usually disappears after only a few cycles. The first feature at $1.7 \mathrm{~V}$ has been attributed to the $\mathrm{Cu}^{2+} / \mathrm{Cu}^{+}$redox couple and the second feature at $1.8 \mathrm{~V}$ to the $\mathrm{Fe}^{3+} / \mathrm{Fe}^{2+}$ redox couple. ${ }^{38,39}$ Both these peaks progressively shift to higher average potentials with cycling, although the first feature decreases in size significantly, whereas the second feature instead increases with cycling while shifting to higher potential (i.e., from $1.8 \mathrm{~V}$ to $1.9-2.0 \mathrm{~V}$ ), see Figure $1 \mathrm{a}$. The same set of peaks is present on the cathodic sweep (i.e., during discharge $/ \mathrm{Zn}^{2+}$ "insertion" or swapping to $4 \mathrm{a}$ vacancy sites), although the peaks shift to slightly lower average potentials with cycling, instead. There are still uncertainties regarding these double features and the underlying mechanism that causes them to change with cycling. It was speculated early on whether these are influenced by electrostatic repulsion from the insertion of the divalent $\mathrm{Zn}^{2+}$ ion $^{18}$ and more recently by the evolution of new $\mathrm{Zn}$-rich phases $\left(\mathrm{Zn}_{\mathrm{x}} \mathrm{Cu}_{1-\mathrm{x}} \mathrm{HCF}\right)$ due to the irreversible trapping of $\mathrm{Zn}^{2+}$ ions in $\mathrm{Fe}(\mathrm{CN})_{6}$ vacancies of $\mathrm{CuHCF} .^{28,29,32,33} \mathrm{~A}$ thorough investigation of these peaks and how they correlate with the electroactivity of $\mathrm{Cu}$ and $\mathrm{Fe}$ sites will be presented in this study.

The galvanostatic voltage profiles at $\sim 8 \mathrm{C}$ cycling rate are shown in Figure $1 \mathrm{~b}$. Based on the loadings of the active material determined from ICP-OES, the gravimetric capacity of our CuHCF material is on average $64 \pm 10 \mathrm{mAh} \mathrm{g}^{-1}$ at $8 \mathrm{C}$, which is in line with the proposed theoretical capacity of this material. ${ }^{18}$ We note that at slower rates, more capacity can be accessed, and at $1 \mathrm{C}$, the cell delivers a practical charge/ discharge capacity of $81 \pm 9 \mathrm{mAh} \mathrm{g}^{-1}$ (Figure S2a,b). This is slightly higher than the initially proposed capacity; however, our calculations support these as the expected capacities based on the differences in the electron transfer number at different cycling rates (Figure S2c,d and eqs $\mathrm{S} 1-\mathrm{S} 5$ ). It is also in line with the study by Jiang et al., ${ }^{26}$ who reported a theoretical capacity of $87 \mathrm{mAh} \mathrm{g}^{-1}$, and with Naveed et al., ${ }^{40}$ who reported a capacity of $73 \mathrm{mAh} \mathrm{g}^{-1}$ for their $\mathrm{Zn} / \mathrm{CuHCF}$ cells. It should be kept in mind that the capacity depends on several parameters, such as the number of water molecules in the structure (related to the molecular weight), the electron transfer number (i.e., $n$, the number of $\mathrm{e}^{-}$transferred per metal site), and the loading of the active material. These are often challenging to determine precisely by experiments, since they may vary during the electrochemical reaction. Thus, the delivered practical charge/discharge capacities may not always perfectly agree with the theoretical or expected capacities. The operational voltage of our $\mathrm{Zn} / \mathrm{CuHCF}$ cell is initially $\sim 1.65 \mathrm{~V}$, with an average Coulombic efficiency of $\sim 99.2 \%$ over 200 cycles and a round-trip efficiency of $\sim 89.7 \%$ (Figure $1 \mathrm{~d}$ and eq S6). The capacity nevertheless fades with cycling, and $\sim 15-$ $20 \%$ of the initial capacity is lost after 200 cycles at $8 \mathrm{C}$ (ca. 56 $\mathrm{h}$ of continuous cycling). This is linked to the appearance of a sloping two-phase plateau, which is often reported as a characteristic aging effect in CuHCF (Figure 1b,c). ${ }^{31}$ The charging plateau shifts to higher average potentials compared to the discharge curve (Figures $1 \mathrm{~b}$ and S2e). This highlights an asymmetry between the charge/discharge processes that evolves with cycling, which is likely related to differences between the anode $\mathrm{Zn}$ stripping/plating or the cathode $\mathrm{Zn}$ deinsertion/insertion processes. Electrochemical impedance 
a)

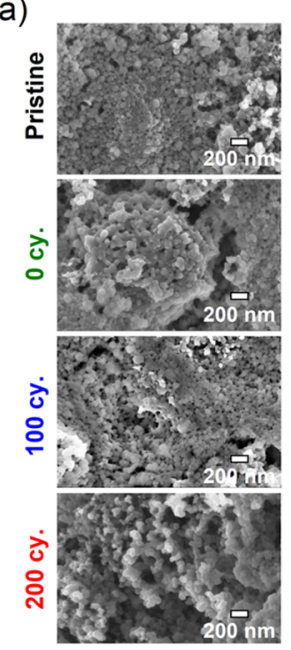

b)

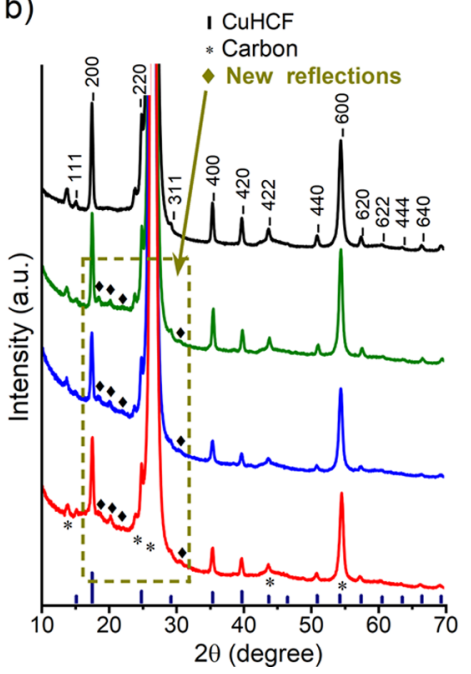

c)

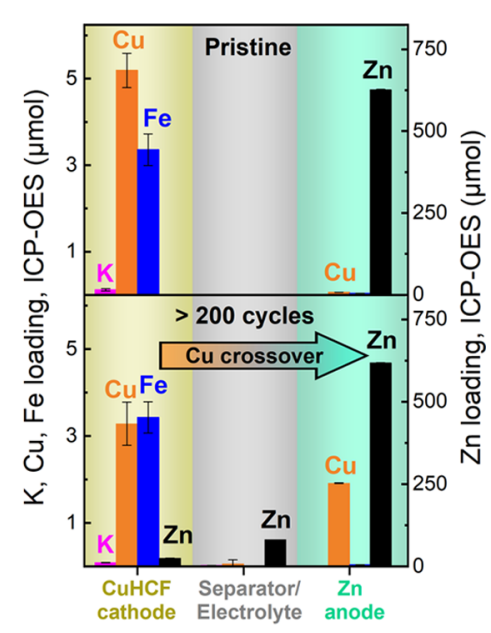

Figure 2. Aging of the aqueous $\mathrm{Zn} / \mathrm{CuHCF}$ cell after cycling in $1 \mathrm{M} \mathrm{ZnSO}$ between 1.00 and $2.15 \mathrm{~V}$ at $\sim 8 \mathrm{C}$ and stopping the cells at $\mathrm{OCP}$. (a) SEM micrographs of the CuHCF cathode; pristine (black), 0 cycles (i.e., resting $1 \mathrm{~h}$ at OCP, green), after 100 cycles (blue), and after 200 cycles (red). (b) Corresponding XRD patterns of the CuHCF cathode between 10 and $70^{\circ}$ in the $2 \theta$ angular range; the color code in (a) also applies here. (c) Elemental analysis of the $\mathrm{Zn} / \mathrm{CuHCF}$ cell parts using ICP-OES (cathode, separator/electrolyte, and anode). Top: the pristine state. Bottom: after $200 \mathrm{CV}$ cycles. The bars represent the metal loadings of $\mathrm{K}, \mathrm{Cu}, \mathrm{Fe}$, and $\mathrm{Zn}$, where the cathode area is shaded in yellow (left), the separator is shaded in gray (middle), and the $\mathrm{Zn}$ anode is shaded in light green (right). Note that all samples were rinsed with ultrapure water prior to the analysis to remove excess $\mathrm{ZnSO}_{4}$ except in the case of (c), where we intended to preserve ionic species.

spectroscopy confirmed an increase in the cell resistance $\left(R_{\mathrm{w}}\right.$ iR-drop) by $\sim 60 \%$ from $\sim 5$ to $\sim 8 \Omega$ after 200 cycles (Figure S2f). Recovery tests by introducing an aimed pause of $24 \mathrm{~h}$ after completing 200 cycles show that the initial capacity cannot be recovered by this protocol and should therefore be regarded as an irreversible charge loss (Figure S3). Contributions from other processes, such as the stability of $\mathrm{CuHCF}$ and the redox activity of $\mathrm{Cu}$ and $\mathrm{Fe}$ centers to this aging behavior, will be investigated in detail in the sections below.

2.2. Structure-Related Aging Effects of CuHCF. Scanning electron microscopy (SEM) shows that CuHCF is composed of particles with an average size of $\sim 50 \mathrm{~nm}$ (Figures $2 \mathrm{a}$ and $\mathrm{S} 4$ ). The XRD pattern can be indexed with a cubic unit cell $(\mathrm{Fm} \overline{3} \mathrm{~m})$, in accordance with a previous study by Renman et al. of this material (Figure 2b). ${ }^{31}$ The CB and graphite foil, used as conductive additive and current collector, respectively, also give rise to additional background diffraction peaks, marked with asterisks in Figure $2 \mathrm{~b}$. The XRD pattern of the pure $\mathrm{CuHCF}$ powder without the additions of $\mathrm{CB}$ or PVA binder is shown in Figure S5a, where it is compared to the patterns of the bare graphite foil and the CB-PVA cast without active material. Upon electrochemical cycling in $1 \mathrm{M} \mathrm{ZnSO}_{4}$, there are no obvious morphological changes of the $\mathrm{CuHCF}$ cathode. However, there is a set of new diffraction peaks appearing at $18.5,20.2,22.0$, and $30.5^{\circ}$ (Figures $2 \mathrm{~b}$ and S5b). These actually become visible already after 0 cycles, which corresponds to resting the cell for $1 \mathrm{~h}$ at open-circuit potential (OCP), although they progressively intensify with cycling. In previous studies, new diffraction peaks were reported in similar $\mathrm{CuHCF}$ cathodes, which are currently thought to be related to these new $\mathrm{ZnHCF}$ (or mixed $\mathrm{Zn}_{x} \mathrm{Cu}_{1-x} \mathrm{HCF}$ ) phases caused by the irreversible trapping of $\mathrm{Zn}^{2+}$ ions inside the framework. $^{30,32,34}$ These peaks usually appear at later stages of cycling (typically after $\sim 250-500$ cycles), along with clear morphological changes, where both wires and cubes have been reported. Here, we do not observe any changes in the morphology, and the new diffraction peaks that appear at relatively early stages of cycling do not match with the proposed $\mathrm{Zn}_{x} \mathrm{Cu}_{1-x} \mathrm{HCF}$ phases. We note that Lim et al. ${ }^{30}$ also reported changes in their patterns after 0 cycles, directly after immersing the CuHCF cathode in the electrolyte. These peaks could also not be conclusively identified. In the cathode of $\mathrm{Zn} /$ $\mathrm{MnO}_{2}$ cells (in the presence of electrolyte $\mathrm{Mn}^{2+}$ ions), Chamoun et al. $^{41}$ reported new diffraction peaks associated with a layered Zn-buserite phase during charge, and a zinc sulfate hydroxide phase during discharge. In $\mathrm{Mn}^{2+}$-free electrolytes, they observed some degree of $\mathrm{Zn}^{2+}$ trapping in the cathode similar to that in CuHCF, although hydroxide formation from $\mathrm{H}^{+}$insertion was suppressed. It is therefore important to verify phase transformations and possible contributions from oxidic phases also in our CuHCF cathode.

Elemental compositions from energy-dispersive X-ray spectroscopy (EDS) show negligible changes in the relative oxygen content of the CuHCF cathode. This is in contrast to the $\mathrm{Zn}$ anode where the $\mathrm{O}$ content increases by $\sim 60$ at. $\%$ after 200 cycles (Figure S6). EDS also confirms a relative loss of $\mathrm{Cu}$ that amounts to $\sim 30$ at. \% after 200 cycles, seen as a decrease in the $\mathrm{Cu} / \mathrm{Fe}$ ratio from $\sim 1.5$ to $\sim 1.0$ (see Table $\mathrm{S} 1$ ). The loss of $\mathrm{Cu}$ is verified by ICP-OES, where the complete cell was analyzed part by part (cathode, separator/electrolyte, and anode). This confirms the loss of the original $\mathrm{Cu}$ content of $\mathrm{CuHCF}$ by $~ 30$ at. \% after 200 cycles, and shows that $\mathrm{Cu}$ crosses over to the $\mathrm{Zn}$ anode (Figure $2 \mathrm{c}$ and Table S2). ICP-OES further verifies that the $\mathrm{Cu}$ content increases progressively with cycling on the $\mathrm{Zn}$ anode (Figure S7). We do not observe any loss of Fe, which confirms that $\mathrm{Cu}$ is the unstable species in CuHCF, in accordance with previous studies. ${ }^{28-32}$

In the $\mathrm{Zn}$ anode, SEM images reveal a platelet-like structure that appears in correlation with the emergence of diffraction peaks that match with a zinc sulfate hydroxide hydrate phase $\left[3 \mathrm{Zn}(\mathrm{OH})_{2} \cdot \mathrm{ZnSO}_{4} \cdot 4 \mathrm{H}_{2} \mathrm{O}\right]$ (Figure S8). ${ }^{42}$ This phase will be denoted shortly as " $\mathrm{Zn}(\mathrm{OH})_{2}$ ". A $\mathrm{ZnO}$ phase was reported on the $\mathrm{Zn}$ anode by Trócoli and La Mantia, ${ }^{18}$ which is different 
from the phase we detect here. We further observe small $\mathrm{Cu}$ rich nanoparticles that decorate the $\mathrm{Zn}$ anode, which verifies that $\mathrm{Cu}$ crosses over (Figures S9 and S10). These particles are visible already after 0 cycles; however, they grow larger with cycling. The subsequent crossover and nucletion of $\mathrm{Cu}$ ions on the $\mathrm{Zn}$ anode after dissolution from $\mathrm{CuHCF}$ may explain why significant amounts of $\mathrm{Cu}$ impurities are rarely detected in the electrolyte.

What puzzles us is the significant loss of $\mathrm{Cu}$ from $\mathrm{CuHFC}$ already after 0 cycles (i.e., after resting the cell for $\sim 1 \mathrm{~h}$ at the OCP). This motivated us to investigate the spontaneity of this dissolution process closer. Using ICP-OES, we compared cycled cells with cells left resting at OCP for the same amount of time it takes to complete 0,100 , and 200 charge/discharge cycles (ca. $1 \mathrm{~h}, 27 \mathrm{~h}, 56 \mathrm{~h}$ ). The results show that equal amounts of $\mathrm{Cu}$ are lost both after resting and after cycling the cells (Figure S11). The loss of $\mathrm{Cu}$ after $\sim 56 \mathrm{~h}$ at OCP amounts to $21 \pm 4 \mathrm{wt} \%$ and after 200 cycles it amounts to $26 \pm 11 \mathrm{wt}$ $\%$. Notably, despite similar losses of the active material, the capacity retention is significantly higher after resting the cell at OCP $(3.5 \pm 0.2 \%)$ compared to cycling $(18 \pm 4 \%)$ (see Figure S12). This advocates that there are other detrimental processes resulting in performance loss during cycling, which will have to be investigated in future studies. Our results conclude that the $\mathrm{Cu}$ dissolution from $\mathrm{CuHCF}$ is indeed spontaneous. Since time appears to be the prime factor determining the aging, faster cycling rates could result in a relatively higher charge retention since it takes a shorter time to complete a cycle. This may result in inconsitencies across studies depending on the cycling protocol.

Lastly, we cross-checked the stability in $0.1,1$, and $2 \mathrm{M}$ $\mathrm{ZnSO}_{4}$, since the concentration has been demonstrated to be an important stability parameter in $\mathrm{CuHCF}^{32}$ We find the lowest stability in $2 \mathrm{M}$; however, there is no difference between 0.1 and $1 \mathrm{M} \mathrm{ZnSO}_{4}$ (Figure S13a,b). This is in contrast to earlier studies where lower concentrations were correlated with higher charge retention. ${ }^{32}$ Instead, we observe a significant increase in the cell resistance in $0.1 \mathrm{M} \mathrm{ZnSO}_{4}$, which leads to distortions of the redox peaks and unfavorable $\mathrm{Zn}^{2+}$ insertion (Figure S13c-f). Most cells cycled with $0.1 \mathrm{M} \mathrm{ZnSO}_{4}$ fail even before completing 100 cycles. We therefore conclude that $1 \mathrm{M}$ $\mathrm{ZnSO}_{4}$ is the optimal condition for our system.

2.3. STEM and EDS Mapping. To resolve the CuHCF particles better, we performed HAADF-STEM and EDS elemental mapping (Figure 3). In the pristine CuHCF cathode (containing PVA binder and CB conductive additive), there is a weak signal of $\mathrm{K}$ (likely impurities from the synthesis) and signals of $\mathrm{N}, \mathrm{C}, \mathrm{Fe}$, and $\mathrm{Cu}$ belonging to CuHCF (Figure S14). There is also a weak signal of $\mathrm{O}$ distributed in the bulk of the pristine $\mathrm{CuHCF}$ particles, which could originate from the water in the structure, or possibly from the PVA or CB. Note that the $\mathrm{C}$ signal could also originate from PVA or $\mathrm{CB}$, and there is a substantial $\mathrm{Cu}$ signal from the TEM grid. There are no signals from either $\mathrm{Zn}$ or $\mathrm{S}$ in the pristine sample. After 200 cycles in $1 \mathrm{M} \mathrm{ZnSO}_{4}$, the signal of $\mathrm{K}$ disappears, and new signals of $\mathrm{Zn}$ and $\mathrm{S}$ appear (Figure S15). Also, a thin layer of $\mathrm{O}$ enrichment is clearly notable on the outermost surface of the cycled particles, which was not visible in the pristine $\mathrm{CuHCF}$ particles (Figure 3). This $\mathrm{O}$ signal is nevertheless relatively weak, requires long acquisition times to be resolved, and is also somewhat segregated from the $\mathrm{Zn}$ (and $\mathrm{Cu}, \mathrm{Fe}$ ) signals. This suggests that these elements do not belong to the same phase. Therefore, we suspect that the surface $\mathrm{O}$ enrichment is related


Figure 3. HAADF-STEM and EDS elemental maps of the CuHCF cathode after $200 \mathrm{CV}$ cycles between 1.00 and $2.15 \mathrm{~V}$ in $1 \mathrm{M} \mathrm{ZnSO}_{4}$. The EDS maps of elements belonging to the CuHCF material are shown in the top row $(\mathrm{Cu}$ and $\mathrm{Fe}$ ) and elements that appear after cycling in the left column ( $\mathrm{Zn}, \mathrm{O}$, and S). Selected composite maps are labeled with the respective elements. The analyzed particles had been rinsed with ultrapure water prior to the analysis to remove excess $\mathrm{ZnSO}_{4}$ electrolyte. The scale bar is $50 \mathrm{~nm}$.

to other species than oxidic phases, which will be further investigated in Section 2.5.1 below. The elemental compositions from HAADF-STEM analysis are provided in Table S3.

2.4. Identification of XRD Peaks at the Early Stages of Cycling. In search for a more solid explanation for the yet unidentified diffraction peaks that appear during the early stages of cycling in the CuHCF cathode, we investigated two control cells in which the active material was intentionally left out from the electrode coating. The idea was to examine whether these peaks could be related to other constituents of the cathode, such as graphitic carbon, which is often used as a conductive additive and can intercalate ions. ${ }^{43,44}$ The two control cells (denoted as "blank" cells) consisted of either CBPVA (i.e., $\mathrm{Zn} / \mathrm{CB}-\mathrm{PVA}$ ) or bare graphite foil (i.e., $\mathrm{Zn}$ / graphite). Interestingly, a set of nearly identical diffraction peaks to those seen in the CuHCF cathode also appear in these carbon blank cells after 200 cycles (Figure 4a). In fact, these peaks also emerge already after 0 cycles in these cells (i.e., after $1 \mathrm{~h}$ at OCP), although cycling promotes the peaks especially in the bare graphite cathode (Figure S16). The fact that the peaks are stronger in the graphite cathode compared to the CB-PVA cathode suggests that the new diffraction peaks are related to an intercalation process of $\mathrm{ZnSO}_{4}\left(\mathrm{Zn}^{2+}\right.$ and/or $\left.\mathrm{SO}_{4}{ }^{2-}\right)$ in graphitic carbon. The peaks are also more pronounced in the unwashed (u.w.) samples compared to the washed samples, 
a)

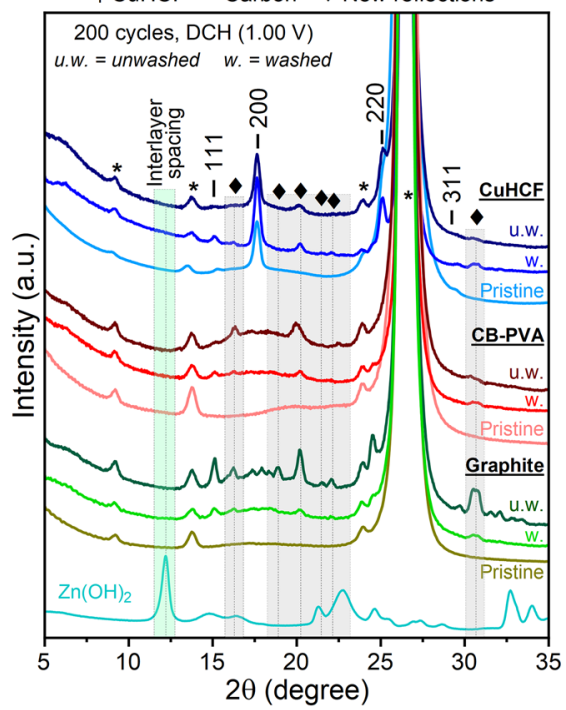

b)

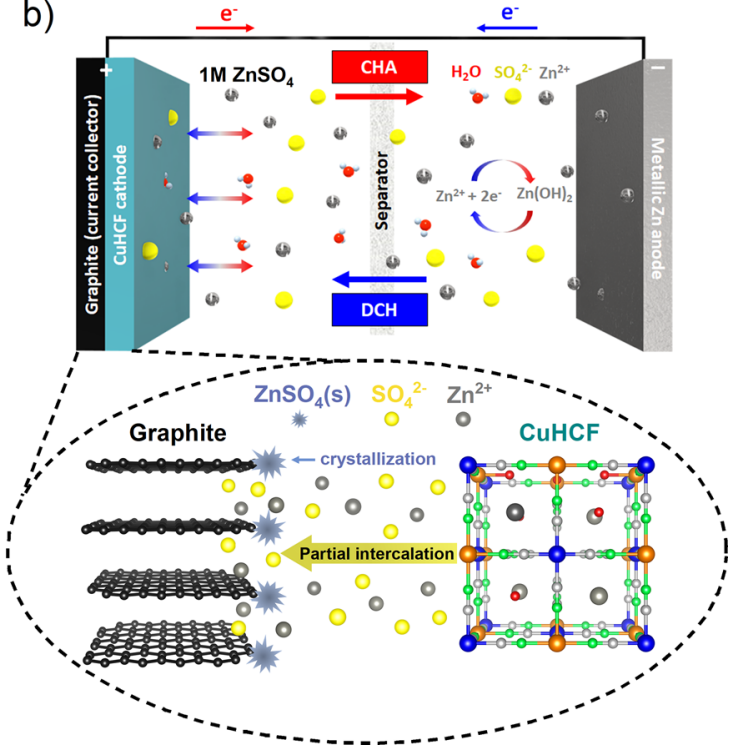

Figure 4. Identification of the XRD patterns of the $\mathrm{Zn} / \mathrm{CuHCF}$ cell. (a) XRD patterns of cathodes: CuHCF and the two carbon "blank" cells (Zn/ CB-PVA and $\mathrm{Zn} /$ graphite) after 200 cycles in $1 \mathrm{M} \mathrm{ZnSO}_{4}$ and stopped in the discharged state (DCH, $1.00 \mathrm{~V}$ ). The washed (w.) and unwashed (u.w.) samples are shown for comparison. The charged state (CHA, 2.15 V) is shown in Figure S17. (b) Schematic representation summarizing the findings from the XRD and Raman spectroscopy analyses, demonstrating that $\mathrm{Zn}^{2+} / \mathrm{SO}_{4}{ }^{2-}$ ions from the electrolyte partially intercalate into graphitic carbon domains and/or crystallize close to the surface regions. The graphics in (b) is highly schematic and does not consider the realistic picture of the solvation shells around the electrolyte ions.

and decrease significantly after the washing step, which indicates that the alleged character of the intercalating species is ionic. The blank cells stopped in the charged state $(2.15 \mathrm{~V})$ exhibit stronger diffraction peaks than the cells stopped in the discharged state $(1.00 \mathrm{~V})$ (Figures $4 \mathrm{a}$ and S17), which indicates that the intercalation process may be initiated during charge. However, since CuHCF modifies the cell potential, the intercalation process of $\mathrm{ZnSO}_{4}$ into carbon may be different in the presence/absence of CuHCF. To judge from the voltammetric profiles of the two carbon blank cells, there is no evidence of any major intercalation processes in the bulk (Figure S18).

Raman spectroscopy confirms a slight increase in the intensity of the characteristic D-band around $1350 \mathrm{~cm}^{-1}$ and the appearance/broadening of the $\mathrm{D}^{\prime}$-feature $\left(\sim 1620 \mathrm{~cm}^{-1}\right)$ in the cycled graphite cathodes (Figure S19). This signifies an increase in the local disorder in graphite, which is consistent with an intercalating species. ${ }^{45}$ There is no difference between the discharged $(1.0 \mathrm{~V})$ and charged $(2.15 \mathrm{~V})$ states; however, the $\mathrm{D}^{\prime}$ feature vanishes after washing the graphite electrodes with water, which supports the proposed ionic character. Furthermore, since the degree of disorder of graphite seen in the Raman spectra is relatively small, it supports that the intercalation process is restricted mainly to the surface regions. In the SEM images, there are small particles clearly visible on the surface of the graphite cathode after cycling, which show signals from Zn, S, and O (Figures S20 and S21 and Table S4). These particles can be removed to a large extent by rinsing the graphite electrode with water, although not completely, which also matches the behavior of the new XRD peaks. The combined picture suggests that these diffraction peaks appearing at early stages of cycling originate from crystallized $\mathrm{ZnSO}_{4}$ at the graphite electrode/electrolyte interface, where a small fraction intercalates into graphitic carbon domains in the surface regions (see the schematic illustration in Figure $4 b$ ).
2.5. Discerning between Surface and Bulk Aging Effects. To probe the electroactive metal centers both at the surface and in the bulk of the cathode during different stages of cycling (pristine and 0, 100, and 200 cycles), we employed a combination of XPS and XAS. These were performed in an "ex situ" configuration, meaning that the cells were disassembled after cycling and prior to the measurements. The cells investigated in this section were stopped at OCP and wahsed with ultrapure water prior to analysis. Information of the charged/discharged states is presented in Section 2.6 below.

2.5.1. Surface Monitored by XPS. The XPS spectra were calibrated to the graphitic carbon peak $\left(\mathrm{sp}^{2}-\mathrm{C}\right)$ at a binding energy (B.E.) of $284.3 \mathrm{eV}$ (Figure 5). ${ }^{46}$ In the $\mathrm{C} 1 \mathrm{~s}$ spectrum, the peak at $285 \mathrm{eV}$ accounts for either adventitious carbon, $\mathrm{C}-$ $\mathrm{H}$, or $\mathrm{C} \equiv \mathrm{N}$ (further denoted just as "CN"), ${ }^{47-52}$ the peak at $\sim 286 \mathrm{eV}$ is assigned to $\mathrm{C}-\mathrm{O}$, and the peak at $\sim 289 \mathrm{eV}$ to $\mathrm{C}=$ $\mathrm{O}$ (Figure S22). ${ }^{46-48}$ These may originate from either CB or the PVA binder. The $\mathrm{Cu} 2 \mathrm{p}_{3 / 2}$ and $\mathrm{Fe} 2 \mathrm{p}_{3 / 2}$ spectra are consistent with $\mathrm{Cu}^{2+}$ and $\mathrm{Fe}^{3+}$ ions in the pristine CuHCF material. With cycling, these are gradually reduced to $\mathrm{Cu}^{+}$and $\mathrm{Fe}^{2+}$. After 200 cycles, the $\mathrm{Cu}^{+}$peak at $932.7 \mathrm{eV}$ has gained intensity, and the $\mathrm{Cu}^{2+}$ peak at $935.6 \mathrm{eV}$ including the $\mathrm{Cu}^{2+}$ satellite peaks at $\sim 944 / 938 \mathrm{eV}$, have disappeared almost completely. Similarly, the $\mathrm{Fe}^{2+}$ peak at $708.2 \mathrm{eV}$ has gained intensity, and the $\mathrm{Fe}^{3+}$ peak at $709.8 \mathrm{eV}$ including the satellite peak at $711.2 \mathrm{eV}$ associated with the unpaired electron in lowspin $\mathrm{Fe}^{3+}$, have disappeared almost completely. This suggests a near complete reduction to $\mathrm{Cu}^{+}$and $\mathrm{Fe}^{2+}$ centers in the surface regions after 200 cycles. The XPS composition confirms the relative loss of both $\mathrm{Cu}$ and $\mathrm{Fe}$, though a more significant loss of $\mathrm{Cu}$, with an associated change in the $\mathrm{Cu} / \mathrm{Fe}$ ratio from 1.4 to 0.2 after 200 cycles (Table S5). This is a more drastic loss of $\mathrm{Cu}$ compared to what we observed for the bulk, which suggests a more significant loss of $\mathrm{Cu}$ at the surface of the $\mathrm{CuHCF}$ particles. 
a)

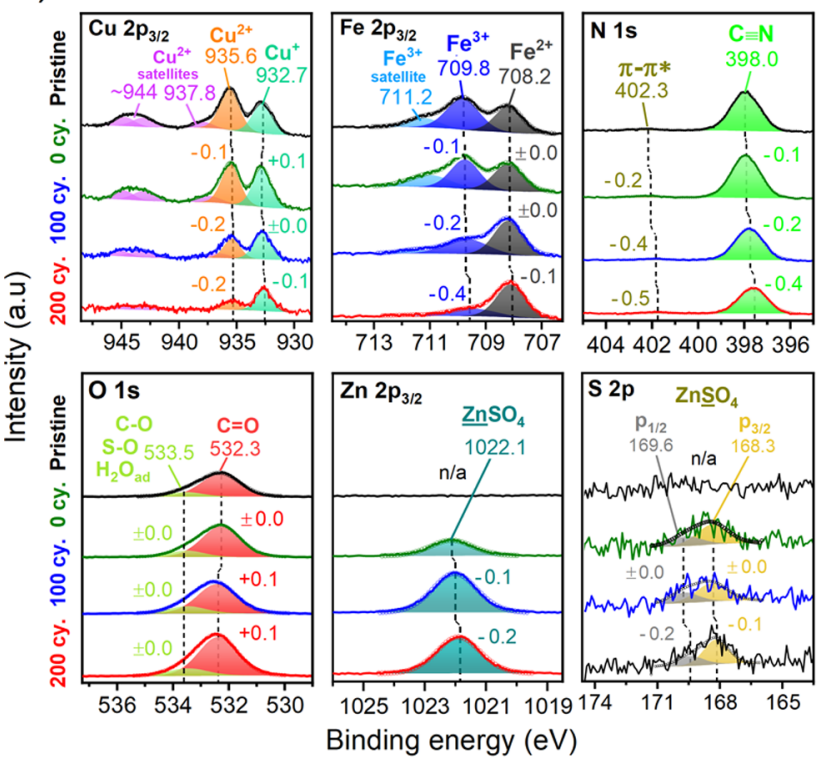

b)

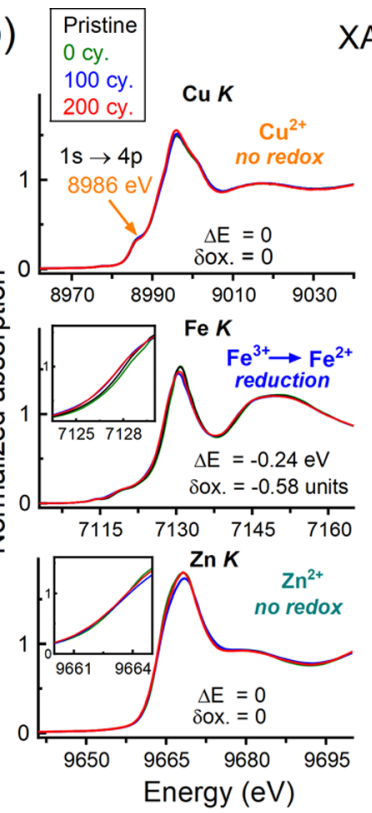

XAS

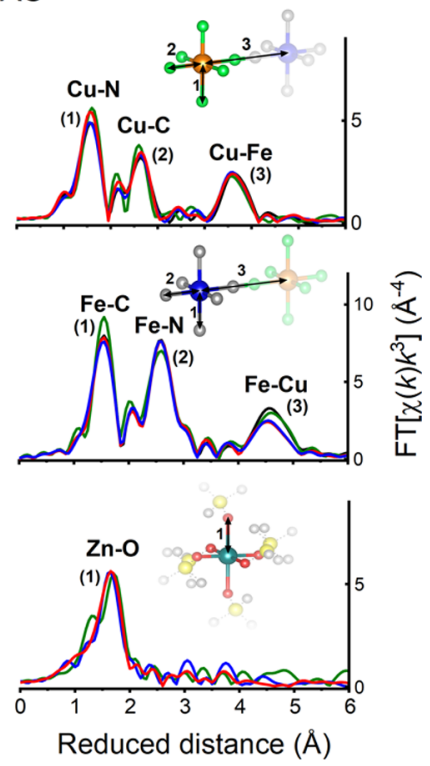

c)

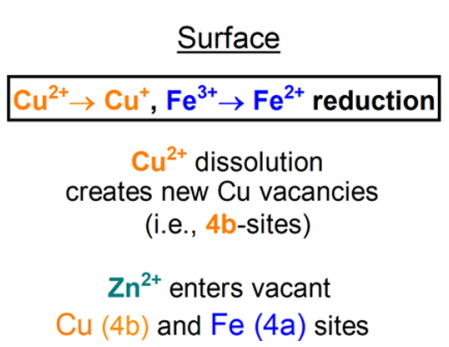

Surface

CuHCF particle

Bulk
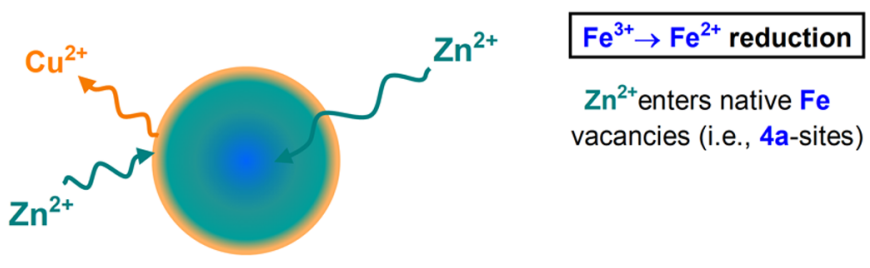

Figure 5. Aging of the CuHCF cathode monitored by XPS and XAS. The Zn/CuHCF cell was subjected to CV cycling between 1.00 and $2.15 \mathrm{~V}$ vs $\mathrm{Zn}^{2+} / \mathrm{Zn}$ at $2.5 \mathrm{mV} \mathrm{s}^{-1}$ in $1 \mathrm{M} \mathrm{ZnSO}_{4}$. (a) XPS after different stages of cycling; pristine, 0 cycles, 100 cycles, and $200 \mathrm{cycles}$. Top: Cu $2 \mathrm{p}_{3 / 2}, \mathrm{Fe}$ $2 \mathrm{p}_{3 / 2}$, and $\mathrm{N} 1 \mathrm{~s}$. Bottom: $\mathrm{O} 1 \mathrm{~s}, \mathrm{Zn} 2 \mathrm{p}_{3 / 2}$, and $\mathrm{S} 2 \mathrm{p}$. The \pm signs denote the relative shift in the B.E. with respect to that in the pristine state. (b) XANES region at the $\mathrm{Cu}, \mathrm{Fe}$, and $\mathrm{Zn} \mathrm{K}$-edges (left panel) and the corresponding FT-EXAFS spectra (right panel). (c) Schematic figures visualizing the findings for the surface and bulk. Note that $\mathrm{Zn}$ was not detected in the pristine CuHCF cathode. All measurements were stopped at the OCP, and the electrodes were rinsed with ultrapure water prior to the analysis to remove excess ionic species from the $\mathrm{ZnSO}_{4}$ electrolyte.

In the $\mathrm{O} 1 \mathrm{~s}$ spectrum, the peak at a B.E. of $\sim 532 \mathrm{eV}$ originates from $\mathrm{C}=\mathrm{O}$, hydrated species such as absorbed $\mathrm{H}_{2} \mathrm{O}$ (zeolitic or coordinating) in $\mathrm{CuHCF}$, or organic $\mathrm{OH}$ species from the PVA binder. ${ }^{48,53,54}$ We allocate the peak at $\sim 533 \mathrm{eV}$ to $\mathrm{C}-\mathrm{O}$ or $\mathrm{SO}$ species from $\mathrm{ZnSO}_{4}{ }^{48,49,55,56}$ however, we could not distinguish between these species within the two envelopes. After 200 cycles, we do not observe any major changes in the $\mathrm{O} 1 \mathrm{~s}$ spectrum, except for an increase in the overall peak area, which is confirmed as an increase in the relative $\mathrm{O}$ content by $\sim 5 \%$ (Table S5).

Most importantly, there is no shift in the B.E. of the $\mathrm{O} 1 \mathrm{~s}$ peaks, or any peaks appearing in the oxide region, which suggests that the nature of these surface $\mathrm{O}$ species (also visible in the HAADF-STEM and EDS mapping) are not oxidic. Since there is a similar increase in the $\mathrm{C}-\mathrm{O}$ component in the $\mathrm{C} 1 \mathrm{~s}$ spectrum (Figure S22), these surface $\mathrm{O}$ species may be related to this.

The $\mathrm{N} 1 \mathrm{~s}$ peak at a B.E. of $298 \mathrm{eV}$ is assigned to the $\mathrm{CN}$ ligand, ${ }^{57}$ which shifts progressively by $0.4 \mathrm{eV}$ to a lower B.E. after 200 cycles. This suggests a change in the electron density around the $\mathrm{CN}$ ligand, ${ }^{58}$ where a shift to a lower B.E. indicates the weakening of the $\mathrm{CN}$ bond. This can be explained by a higher degree of $\pi$-backdonation from the increased electron density around the reduced $\mathrm{Cu}^{+} / \mathrm{Fe}^{2+}$ sites into the $\pi^{*}$ orbital of the $\mathrm{CN}$ bond. ${ }^{58,59}$ In line with this discussion, there is a similar shift of both the $\mathrm{Cu}$ and $\mathrm{Fe} 2 \mathrm{p}$ peaks to a lower B.E. by $\sim 0.3 \mathrm{eV}$ after 200 cycles, which could reflect a change in the electron density, as well. The $\mathrm{Zn} 2 \mathrm{p}_{3 / 2}$ peak at $1021 \mathrm{eV}$ is assigned to $\mathrm{Zn}^{2+}$ ions in $\mathrm{ZnSO}_{4}{ }^{60}$ and increases progressively with cycling, in accord with the proposed mechanism of irreversible trapping of $\mathrm{Zn}^{2+}$ ions in CuHCF. ${ }^{31}$ This correlates well with the changes in both the $\mathrm{Cu}$ and $\mathrm{Fe}$ spectra and suggests that $\mathrm{Zn}^{2+}$ ions enter vacant $\mathrm{Cu}$ and $\mathrm{Fe}$ sites, inducing a reduction of these sites. The $S 2 p$ peak at $168-170 \mathrm{eV}$ is assigned to $\mathrm{S}$ species in $\mathrm{ZnSO}_{4}{ }^{60,61}$ and a signal appears after 0 cycles (i.e., after $1 \mathrm{~h}$ at OCP) and then increases only moderately with cycling. The initial traces of $\mathrm{K}^{+}(\sim 0.1 \%)$ from the synthesis also disappear in the cycled samples (Figure S22).

For the sake of completeness, we further investigated the spontaneity of the aging process by XPS, whereby we left the $\mathrm{Zn} / \mathrm{CuHCF}$ cells resting at OCP for the same amount of time that it takes to cycle 0,100 , and 200 cycles. Indeed, nearly identical changes occur in these CuHCF samples not exposed to cycling (Figure S23 and Table S6), which confirms that the aging process at the surface indeed is also spontaneous. XPS spectra of the relevant reference compounds in this context are provided in Figure S24. 


\section{a)}

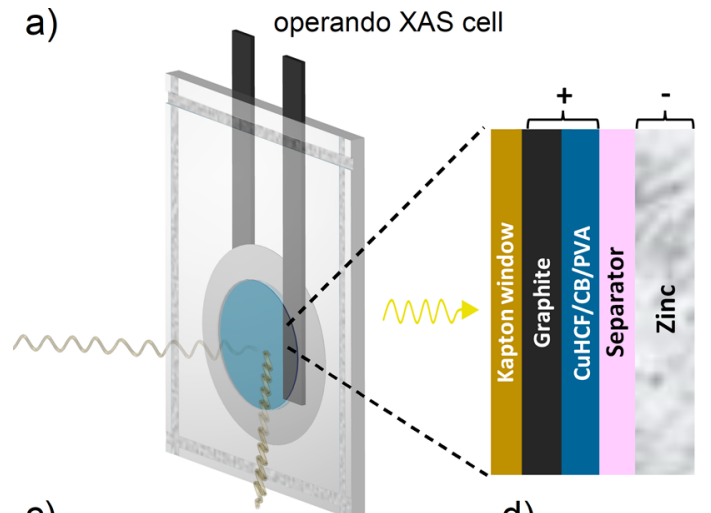

c)

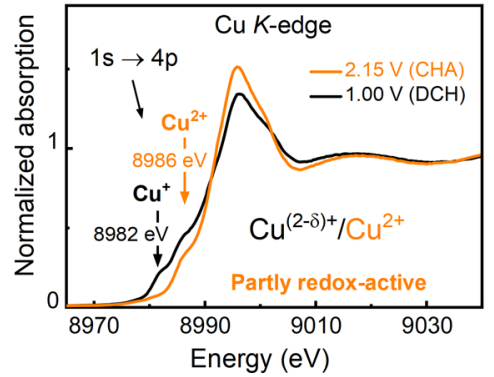

d)

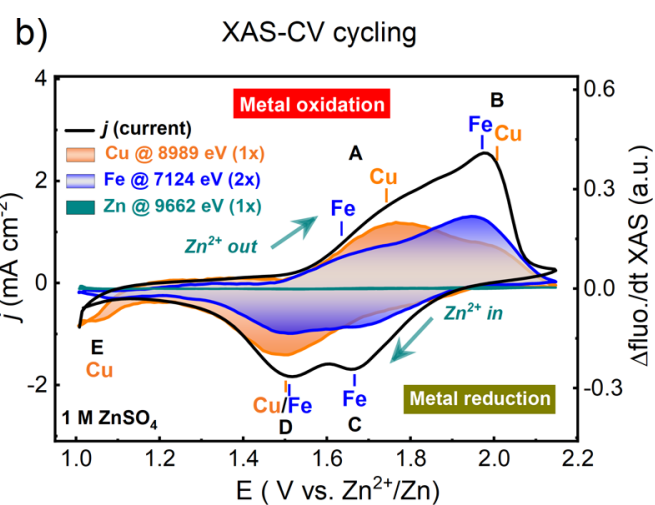

e)
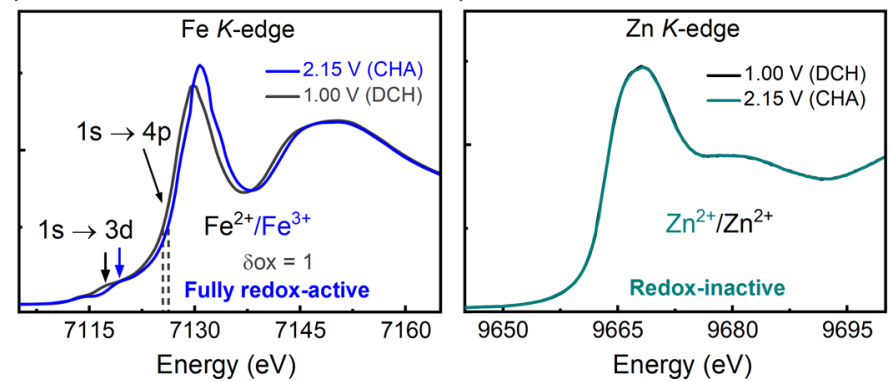

Figure 6. In situ XAS of the CuHCF cathode. (a) Schematic view of the XAS cell setup, consisting of a pouch cell with an X-ray transparent Kapton window. The fluorescence was monitored from the backside through the graphite foil. (b) Potentiodynamic XAS-CV cycling experiments carried out in the "operando" mode, where the fluorescence is monitored at the $\mathrm{Cu}, \mathrm{Fe}$, and $\mathrm{Zn}$ K-edges during cyclic voltammetry between 1.00 and 2.15 $\mathrm{V}$ in $1 \mathrm{M} \mathrm{ZnSO}_{4}$. The current density $(j)$ is shown as a black curve, and the shaded areas correspond to the first derivative of the fluorescence, derived from the $\mathrm{Cu}$ K-edge (orange), Fe K-edge (blue), and Zn K-edge (dark cyan). The positive shaded areas represent an oxidation process, and the negative areas represent a reduction process. The Fe fluorescence has been scaled up 2 times $(2 \times)$ for comparison reasons; however, the axis does not scale with the absolute oxidation states. The XANES region in the discharged (1.00 V) and charged (2.15 V) states are shown for the different metal sites: (c) Cu K-edge, (d) Fe K-edge, and (e) Zn K-edge.

2.5.2. Bulk Monitored by XAS. The redox activity in the bulk of $\mathrm{CuHCF}$ was probed by XAS at the $\mathrm{Cu}, \mathrm{Fe}$, and $\mathrm{Zn} \mathrm{K}$ edges. The X-ray absorption near-edge structure (XANES) of the pristine CuHCF cathode is shown in Figure 5b (left panel) and exhibits a typical signature of metal hexacyanoferrates composed of linear $\mathrm{Fe}-\mathrm{CN}-\mathrm{Cu}$ units with the metal centers in an octahedral coordination. ${ }^{27,36}$ The Fe atom is connected to the $\mathrm{C}$-end of the cyanide ligand and resides in a low-spin state, whereas the $\mathrm{Cu}$ atom is connected to the $\mathrm{N}$-end and resides in a high-spin state.

The $\mathrm{Cu}$ XANES of the pristine cathode has a shoulder at $\sim 8986 \mathrm{eV}$ (i.e., the dipole-allowed $1 \mathrm{~s} \rightarrow 4 \mathrm{p}$ transition) and a weak prefeature at $\sim 8977 \mathrm{eV}$ (i.e., the quadruple-allowed $1 \mathrm{~s} \rightarrow$ $3 \mathrm{~d}$ transition), which is a signature of $\mathrm{Cu}^{2+}$ in the $\mathrm{d}^{9}$ state with one unpaired electron (Figure 5b, top left, and Table S7). ${ }^{36,62}$ The Fe oxidation state is more straightforward and can be obtained from the edge position at half-height. We primarily find $\mathrm{Fe}^{3+}$ in the pristine sample (Figure $5 \mathrm{~b}$, middle left). The $\mathrm{Zn} \mathrm{K}$-edge is largely insensitive to the oxidation state; ${ }^{63}$ however, based on the spectral shape around the XANES region, we confirm dominating $\mathrm{Zn}^{2+}$ ions in an octahedral coordination environment (Figure $5 \mathrm{~b}$, bottom left, and Table S7). ${ }^{53,64}$ After cycling (up to 200 cycles), there are no visible changes in the $\mathrm{Cu}$ spectra; however, in the $\mathrm{Fe}$ spectra, the edge position progressively shifts by $0.4 \mathrm{eV}$ to lower energies. Lowspin Fe shifts less than high-spin $\mathrm{Fe}$, and the expected edge shift is $\sim 0.65 \mathrm{eV}$ per oxidation state (see reference compounds in Figure S25 and Table S8). Our data is consistent with $\sim 60 \%$ of the $\mathrm{Fe}$ centers being reduced from $\mathrm{Fe}^{3+} \rightarrow \mathrm{Fe}^{2+}$ after 200 cycles. The $\mathrm{Cu}$ K-edge shows no change in the XANES region, with predominant $\mathrm{Cu}^{2+}$ species both in the pristine state and after 200 cycles. This suggests that the majority of the $\mathrm{Cu}$ species in the bulk are not redox-active. This is surprising since the XPS data clearly shows an almost complete reduction of both $\mathrm{Fe}$ and $\mathrm{Cu}$ sites at the surface. Our combined XAS and XPS data therefore suggest that the $\mathrm{Cu}^{2+} \rightarrow \mathrm{Cu}^{+}$reduction happens mainly at the surface of the CuHCF particles, and is therefore likely related to the vacancies created upon $\mathrm{Cu}$ dissolution. There are no changes around the $\mathrm{Zn} \mathrm{K}$-edge in the cycled electrodes, whereby we conclude that $\mathrm{Zn}^{2+}$ ions are the predominant species without any changes upon cycling.

The local atomic structure parameters were obtained from simulations of the $k^{3}$-weighed extended X-ray absorption fine structure (EXAFS) using scattering functions generated in FEFF. The Fourier transform EXAFS (FT-EXAFS) spectra are shown in Figure 5b (right panel) and Figure S26. The approach was adopted from previous studies ${ }^{27,65,66}$ and is described in detail in the Experimental Section in the Supporting Information. The FT-EXAFS spectra reveal three dominating peaks in $\mathrm{CuHCF}$, where the $\mathrm{Cu}$ K-edge exhibits a $\mathrm{Cu}-\mathrm{N}$ shell at $\sim 1.95 \AA$, a $\mathrm{Cu}-\mathrm{C}$ shell at $\sim 3.11 \AA$, and a $\mathrm{Cu}-$ Fe shell at $\sim 4.9 \AA$. The Zn K-edge, which appears first after 0 cycles after resting the cell for $1 \mathrm{~h}$ at OCP, exhibits only a $\mathrm{Zn}-$ O scattering shell at $\sim 2.08 \AA$, which can be simulated with $\sim 6$ oxygen ligands (see fit parameters in Tables S9 and S10). There are no major changes around this shell with cycling. Since this type of PBAs practically behaves as zero-strain materials, very little volume or structural changes are expected upon cation deinsertion/insertion and subsequent metal oxidation/reduction. Indeed, the variations in the EXAFS 
domains are too small to be detected herein. Our combined XPS and XAS data confirm no changes around the Zn K-edge XANES region, which also excludes the formation of new $\mathrm{Zn}_{x} \mathrm{Cu}_{1-x} \mathrm{HCF}$ phases up to 200 cycles, which have been reported between 250 and 1000 cycles in previous studies. $^{30,32,34}$ Such phases may hence form at later stages of cycling, which will be addressed in future work. Our data further conclude that the $\mathrm{Fe}^{3+} / \mathrm{Fe}^{2+}$ redox couple is active in the entire bulk, while the $\mathrm{Cu}^{2+} / \mathrm{Cu}^{+}$redox couple mainly is restricted to the surface of the CuHCF particles. This is consistent with $\mathrm{Zn}^{2+}$ trapping both in vacant Fe sites (Wyckoff notation as 4a) throughout the bulk, and in vacant $\mathrm{Cu}$ sites (Wyckoff notation as $4 \mathrm{~b}$ ) at the surface, the latter of which is triggered by $\mathrm{Cu}$ dissolution (see the schematic illustration in Figure 5c).

2.6. Probing Electroactive Sites Using In Situ XAS. XAS in an "in situ" configuration was carried out using a pouch cell with an X-ray transparent Kapton window, and the fluorescence was monitored from the back side of the graphite current collector, which can be considered as X-ray transparent (see Figure 6a).

2.6.1. Potentiodynamic XAS during CV Cycling. The $\mathrm{XAS}-\mathrm{CV}$ cycling studies we refer specifically to as "operando", and these were carried out in a potentiodynamic fashion where the fluorescence was monitored at a fixed energy during a complete cyclic voltammetric sweep between 1.00 and $2.15 \mathrm{~V}$ in $1 \mathrm{M} \mathrm{ZnSO}_{4}$. This allowed a fine correlation between the electroactive species and the redox peaks in CuHCF.

The fluorescence was monitored at $8989 \mathrm{eV}$ for the $\mathrm{Cu} \mathrm{K}$ edge, at $7126 \mathrm{eV}$ for the Fe K-edge, and at $9660 \mathrm{eV}$ for the $\mathrm{Zn}$ K-edge. The derivative of the fluorescence was aligned with the $\mathrm{CV}$ curves in a postprocessing step, although the signal from the Keithley instrument was recorded in the analog input of the potentiostat to ensure accurate translation. The data curves shown in Figure $6 \mathrm{~b}$ are the averages of three consecutive CV cycles to reduce the noise level (no major differences were observed between the consecutive cycles). On the anodic sweep (i.e., during the charging process), the first redox peak at $\sim 1.75 \mathrm{~V}$ (peak $\mathrm{A}$ in Figure $6 \mathrm{~b}$ ) can be identified as $\mathrm{Cu}$ oxidation. However, there is a weak pre-feature occurring at $\sim 1.65 \mathrm{~V}$ that originates from Fe oxidation. The second main anodic redox peak at $\sim 1.9 \mathrm{~V}$ (peak B) increases with cycling and can be identified as $\mathrm{Fe}$ oxidation. However, a weak postfeature at the high-potential side of this peak is also visible at $\sim 2.0 \mathrm{~V}$, which originates from $\mathrm{Cu}$ oxidation. On the cathodic sweep (i.e., during the discharge), the first redox peak at $\sim 1.7$ $\mathrm{V}$ (peak C) can be assigned to Fe reduction, while the second peak at $\sim 1.5 \mathrm{~V}$ (peak D) exhibits contributions from mixed $\mathrm{Cu}$ and $\mathrm{Fe}$ reduction. Another detail we notice is a reductive current starting around $1.1 \mathrm{~V}$ (peak E, Figure 6b), which can be assigned to the $\mathrm{Cu}$ reduction. There are no potentialdependent changes in the $\mathrm{Zn} \mathrm{K}$ fluorescence, which suggests that the $\mathrm{Zn}$ site is redox-inactive. The mixed contributions from both $\mathrm{Cu}$ and $\mathrm{Fe}$ electroactive centers to some of the redox peaks explain the bulky shape of the $\mathrm{CV}$ profile often seen for CuHCF. The fact that the second peak (peak B) on the anodic sweep increases with cycling can be further confirmed as the activation of the $\mathrm{Fe}^{3+} / \mathrm{Fe}^{2+}$ redox couple, most likely due to the $\mathrm{Cu}$ dissolution. A similar activation of $\mathrm{Fe}$ sites was reported by Yang et al. ${ }^{67}$ for an analogous $\mathrm{Zn}-$ FeHCF hybrid battery. A shift of the galvanostatic charge plateau to higher average potentials have also been reported upon cycling of the $\mathrm{Zn} / \mathrm{CuHCF}$ cell, which is thought to be linked to formation of nonstoichiometric $\mathrm{Zn}_{x} \mathrm{Cu}_{1-x} \mathrm{HCF}$ phases and proposed to have a higher cation insertion potential. ${ }^{30,32,34}$ Here, we postulate a new explanation for the shift of the charge/discharge plateaus to higher potentials, which we emphasize can be explained by the increasing contribution from the $\mathrm{Fe}^{3+} / \mathrm{Fe}^{2+}$ redox couple and the decreasing contribution from the $\mathrm{Cu}^{2+} / \mathrm{Cu}^{+}$redox couple due to $\mathrm{Cu}$ dissolution.

2.6.2. XAS in the Charged/Discharged States. To determine the oxidation states in the charged and discharged states, we collected the K-edges while holding the potential at 1.00 and at $2.15 \mathrm{~V}$ during in situ conditions (Figure 6c-e).

In the $\mathrm{Cu}$ K-edge XANES in the charged state $(2.15 \mathrm{~V})$, there is only one peak at $8986 \mathrm{eV}$, which signifies $\mathrm{Cu}^{2+}$, while in the discharged state $(1.00 \mathrm{~V})$, a new peak appears at 8982 $\mathrm{eV}$, associated with $\mathrm{Cu}^{+}$. Although, some signal from $\mathrm{Cu}^{2+}$ still remains. This suggests the partial reduction of $\mathrm{Cu}^{2+} \rightarrow \mathrm{Cu}^{+}$at $1.00 \mathrm{~V}$. The areas under the respective $\mathrm{Cu}^{+}$and $\mathrm{Cu}^{2+}$ peaks are close to 1:1 (Figure S27a); however, we do not make a quantitative estimation of the fractional oxidation states due to the lack of suitable reference compounds. ${ }^{36}$ The Fe site is straightforward since the oxidation state can be obtained from the edge position. In the charged state, we conclude an $\mathrm{Fe}^{3+}$ overall oxidation state. The shift of the $\mathrm{Fe} \mathrm{K}$ edge in the discharged state (at $1.00 \mathrm{~V}$ ) is consistent with $\sim 97 \%$ of the sites being reduced from $\mathrm{Fe}^{3+} \rightarrow \mathrm{Fe}^{2+}$ (Figures 6d and S27b). There are no changes on the $\mathrm{Zn}$ site, in agreement with the operando data. Our results are in line with the XAS studies of CuHCF during $\mathrm{Li}^{+}$-ion insertion by Mullaliu et al., ${ }^{36,65}$ where both $\mathrm{Cu}$ and $\mathrm{Fe}$ sites were confirmed to be electroactive. To the best of our knowledge, there are no in situ XAS studies of CuHCF during $\mathrm{Zn}^{2+}$ insertion in an aqueous electrolyte.

The EXAFS simulations are consistent with minor changes in the local atomic structure parameters upon charge/discharge (Figure S28). During discharge $(2.15 \mathrm{~V} \rightarrow 1.00 \mathrm{~V})$, the $\mathrm{Cu}$ and Fe bond lengths are shortened by $\sim 0.2 \AA$, which corresponds to a contraction of the lattice parameters by $\sim 5-10 \%$ (Tables S9 and S10). This agrees well with previous data of similar lowstrain PBA materials. ${ }^{31}$ There is no change in the local atomic structure parameters around the $\mathrm{Zn}$ K-edge, except for a decrease in the coordination number around the $\mathrm{Zn}-\mathrm{O}$ shell from six to three ligands between the "ex situ" and "in situ" measurements, which we find intriguing (Table S9). We propose that in the "ex situ" measurements, there is a large extent of the dried/crystallized $\mathrm{ZnSO}_{4}$ electrolyte in the surface regions of graphite with $\mathrm{Zn}$ in an octahedral coordination. In the "in situ" configuration, we instead observe a larger extent of hydrated $\mathrm{Zn}^{2+}$ ions occupying the tunnel site in $\mathrm{CuHCF}$, which is analogous to the $\mathrm{A}$ site in the $\mathrm{ABO}_{3}$ perovskite structure, and known to have a tetrahedral coordination. ${ }^{29}$

\subsection{Tracking Species in the Charge Compensation} Process Using XPS. XPS spectra were also ultimately collected in the charged and discharged states. These electrodes were measured in an "ex situ" configuration; however, the cells were stopped either at 1.00 or $2.15 \mathrm{~V}$ before they were disassembled and analyzed.

In the charged state $(2.15 \mathrm{~V})$, both $\mathrm{Cu}^{2+}$ and $\mathrm{Fe}^{3+}$ species are dominating in CuHCF, while in the discharged state $(1.00 \mathrm{~V})$, $\mathrm{Cu}^{+}$and $\mathrm{Fe}^{2+}$ are the dominating species. When comparing with the in situ XAS results in Figure 6a, it indeed looks as if more $\mathrm{Cu}$ sites are electroactive in the surface regions of the CuHCF particles. 
a)

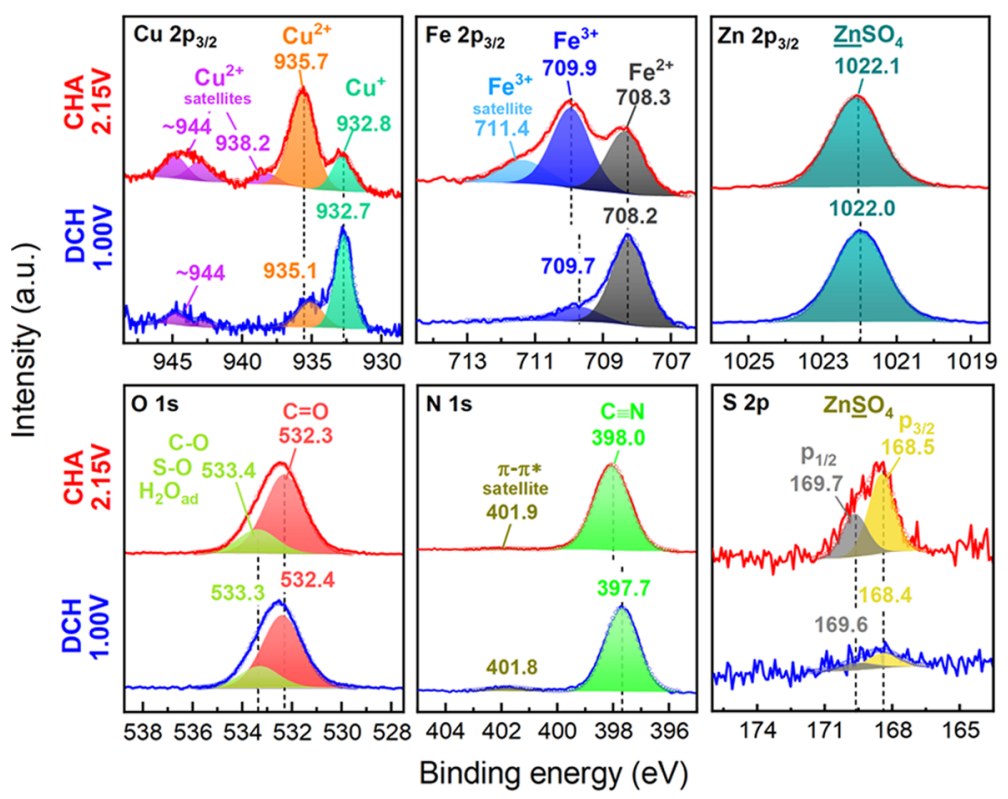

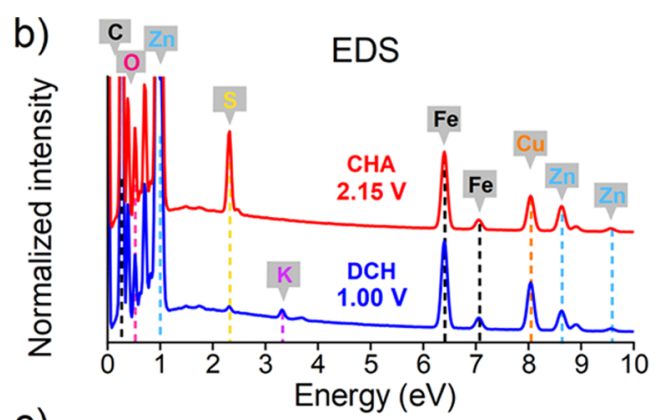

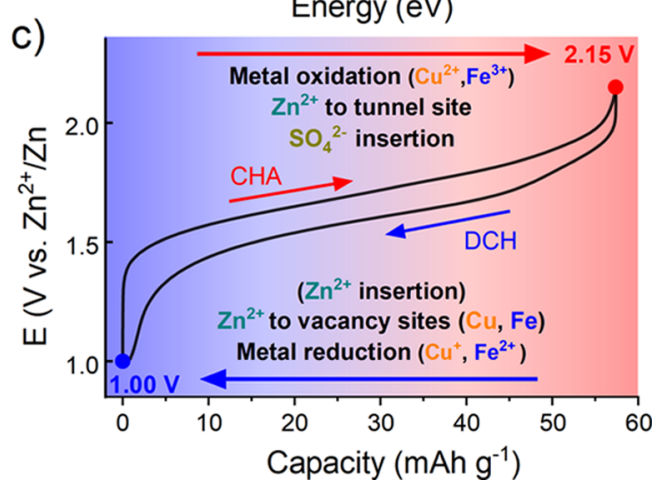

Figure 7. XPS and EDS analyses of CuHCF in the charged and discharged states. (a) XPS spectra of the CuHCF cathode after 200 cycles between 1.00 and $2.15 \mathrm{~V}$ in $1 \mathrm{M} \mathrm{ZnSO}_{4}$ and stopped either in the charged $(2.15 \mathrm{~V})$ or discharged $(1.00 \mathrm{~V})$ state. The $\mathrm{Cu} 2 \mathrm{p}_{3 / 2}$, Fe $2 \mathrm{p}_{3 / 2}$, and $\mathrm{Zn} 2 \mathrm{p}_{3 / 2}$ spectra are shown on the first row, and the $\mathrm{O} 1 \mathrm{~s}, \mathrm{~N} \mathrm{1s}$, and S 2p spectra are shown on the second row. (b) EDS spectra of the cycled CuHCF cathode. The cathodes were rinsed with ultrapure water prior to the analysis to remove the excess $\mathrm{ZnSO}_{4}$ electrolyte. (c) Summary of the findings regarding the charge compensation mechanism of the CuHCF cathode. The black curve represents the charge and discharge voltage profiles during galvanostatic cycling at $8 \mathrm{C}$ rate.

There are no changes in the $\mathrm{Zn} 2 \mathrm{p}$ spectrum, again confirming its redox-inactive nature. Notably, there is also no change in the amount of intercalated $\mathrm{Zn}^{2+}$ ions in the CuHCF structure between the charged and discharges states (Figure 7a, top right). This supports the findings by Renman et al. ${ }^{31}$ and the proposed mechanism that charge compensation proceeds via $\mathrm{Zn}^{2+}$ swapping positions between cavity/tunnel sites (i.e., $8 \mathrm{c}$ sites) and $\mathrm{Fe}(\mathrm{CN})_{6}$ vacancy sites (i.e., 4a sites). Herein, we further present evidence that $\mathrm{Zn}^{2+}$ ions can also enter $\mathrm{Cu}$ vacancy sites (i.e., $4 \mathrm{~b}$ sites) at the surface of the CuHCF particles due to the extensive $\mathrm{Cu}$ dissolution in those regions.

The $\mathrm{N}$ 1s peak assigned to the $\mathrm{CN}$ ligand shifts by $\sim 0.3 \mathrm{eV}$ to a lower B.E. in the charged state $(2.15 \mathrm{~V}$ ) (Figure $7 \mathrm{a}$ ). This was explained earlier as a change in the electron density and the degree of backbonding around the $\mathrm{CN}$ ligand. There are no changes in the $\mathrm{O}$ 1s spectrum, which excludes the suggestion that oxidic phases are formed at the surface of CuHCF during charge/discharge.

Importantly, the intensity of the $\mathrm{S} 2 \mathrm{p}$ peak (i.e., $\mathrm{SO}_{4}{ }^{2-}$ ions) is higher during charge $(2.15 \mathrm{~V})$, and the peak disappears almost completely during discharge $(1.00 \mathrm{~V}$, see Figure $7 \mathrm{a}$, bottom right). Since the CuHCF cathode was rinsed with ultrapure water prior to the analysis, it can be suggested that the $\mathrm{SO}_{4}{ }^{2-}$ anions can be washed away only in the discharged state. Without this washing step, we did not observe any differences in the $\mathrm{S} 2 \mathrm{p}$ spectra during charge/discharge. This indicates that $\mathrm{SO}_{4}{ }^{2-}$ ions are inserted into $\mathrm{CuHCF}$ during charge where they become specifically adsorbed/coordinated to metal centers. Our results suggest that these anions play a role in the charge compensation process. This may further explain the anion dependence observed for these materials. ${ }^{32}$ EDS analysis confirms these findings and also shows that a small amount of $\mathrm{K}^{+}$ions co-insert into CuHCF during discharge (Figure 7b). Nevertheless, CuHCF is known to insert a variety of cations ${ }^{68,69}$ and may insert any species or impurities present in the electrolyte.

In order to exclude the possibility that $\mathrm{SO}_{4}{ }^{2-}$ insertion is not related to an intercalation process in graphitic carbon, in analogy with our observations for the XRD peaks, we aslo collected the same set of XPS data for the two carbon "blank" cells ( $\mathrm{Zn} / \mathrm{CB}-\mathrm{PVA}$ and $\mathrm{Zn} /$ graphite). This concludes that there are no differences in the $S$ content between the charged and discharged states in the carbon blank cells after washing off excess $\mathrm{ZnSO}_{4}$ electrolyte (Figures S29 and S30 and Tables S11 and S12), which conclusively assigns the $\mathrm{SO}_{4}{ }^{2-}$ anion to the charge compensation process in CuHCF. On the other hand, there is some irreversible accumulation of $\mathrm{Zn}$ and $\mathrm{S}$, especially in the graphite cathode, which will have to be investigated in more detail in future studies. We tentatively propose that the $\mathrm{SO}_{4}{ }^{2-}$ ions balance the higher oxidation states of the oxidized $\mathrm{Cu}^{2+}$ and $\mathrm{Fe}^{3+}$ sites during charge. Our findings are summarized in Figure $7 \mathrm{c}$.

\section{CONCLUSIONS}

We provide a highly detailed electrochemical and structural characterization study of the CuHCF cathode employed in aqueous ZIBs. We unravel previously debated aging processes and access new mechanistic findings regarding the charge compensation process. First, we reveal that a set of previously unidentified XRD peaks that appear at early stages of cycling originate from the intercalation of $\mathrm{ZnSO}_{4}\left(\mathrm{Zn}^{2+} / \mathrm{SO}_{4}{ }^{2-}\right)$ and/ or crystallization of these ionic species in the surface regions of graphitic carbon and are therefore unrelated to CuHCF. We further confirm that $\mathrm{Cu}$ is the unstable species and is detrimentally released from CuHCF during cycling. Combined XPS and XAS analysis confirms that $\mathrm{Cu}$ dissolution happens 
mainly in the surface regions of $\mathrm{CuHCF}$, and is spontaneous at the bias imposed at OCP of the $\mathrm{Zn} / \mathrm{CuHCF}$ cell $(\sim 1.7 \mathrm{~V}$ vs $\mathrm{Zn}^{2+} / \mathrm{Zn}$ ). Nevertheless, we find that $\mathrm{Cu}$ dissolution is not solely responsible for the capacity fade. Therefore, future studies need to target the stability of CuHCF and PBAs in more detail to better understand correlations between cycling and effective performance losses in this type of aqueous ZIBs. Using in situ XAS, we confirm that both the $\mathrm{Cu}^{2+} / \mathrm{Cu}^{+}$and $\mathrm{Fe}^{3+} / \mathrm{Fe}^{2+}$ redox couples participate in the charge compensation process, although the $\mathrm{Cu}$ redox couple is more active at the surface-hence correlated to the $\mathrm{Cu}$ vacancies. We conclude that $\mathrm{Zn}^{2+}$ ions can enter these vacant $\mathrm{Cu}$ sites in addition to the native $\mathrm{Fe}(\mathrm{CN})_{6}$ vacancies already present in the structure. Potentiodynamic XAS coupled with cyclic voltammetry establishes a direct link between redox-active metal centers and the voltammetric redox peaks. We thereby conclude that the $\mathrm{Fe}^{3+} / \mathrm{Fe}^{2+}$ couple is activated during repeated cycling due to the $\mathrm{Cu}$ dissolution, and subsequently, the loss of the $\mathrm{Cu}^{2+} / \mathrm{Cu}^{+}$couple. The $\mathrm{Fe}$ redox couple being located at higher average potentials than the $\mathrm{Cu}$ redox couple further explains the progressive increase in the voltage of the anodic redox peak and, analogously, the increase in the potential of the charge/discharge plateaus upon repeated cycling. Finally, we discover that $\mathrm{SO}_{4}{ }^{2-}$ anions participate in the charge compensation process in addition to $\mathrm{Zn}^{2+}$ ions, which reversibly insert into CuHCF during charge. Our study establishes a profound understanding of the aging and the charge compensation processes that impact both directly and indirectly the performance of the aqueous $\mathrm{Zn} / \mathrm{CuHCF}$ cell, which are deemed crucial from the perspective of the strategic design of future PBA-type cathodes for ZIBs and possible improvements of this attractive, yet challenging, $\mathrm{Zn}$-ion rechargeable technology.

\section{ASSOCIATED CONTENT}

\section{SI Supporting Information}

The Supporting Information is available free of charge at https://pubs.acs.org/doi/10.1021/acsami.1c19167.

Experimental procedure (synthesis, electrode cast and assembly of Zn-ion cells, electrochemical characterization, physical characterization, XPS, elemental analysis, XAS analysis, and EXAFS simulations); calculations of the gravimetric capacity, Coulombic efficiency, roundtrip efficiency, and electron transfer number; TGA curve and SEM image of the pristine CuHCF powder; electrochemical characterization, EDS spectra, and elemental compositions from the EDS of the $\mathrm{Zn}$ / CuHCF cell; recovery test combined with cell cycling; $\mathrm{XRD}$ patterns of the cathode side of the $\mathrm{Zn} / \mathrm{CuHCF}$ cell; metal loadings of the components of the $\mathrm{Zn}$ / CuHCF cell; ICP-OES of the $\mathrm{Zn}$ anode; SEM-EDS elemental mapping of the $\mathrm{Zn} / \mathrm{CuHCF}$ cell after 0 and 200 cycles; ICP-OES study and aging characteristics of the CuHCF cathode; impact of the electrolyte concentration on the CuHCF cathode performance and stability; HAADF-STEM and EDS elemental maps of the pristine $\mathrm{CuHCF}$ cathode and the CuHCF cathode after 200 cycles; XRD patterns and EDS analysis of the cathodes in carbon "blank" cells; CV of the carbon "blank" cells: Raman spectra of the $\mathrm{Zn}$ /graphite cell; SEM images of the washed and unwashed cathodes; XPS spectra and elemental compositions of the CuHCF cathode under different conditions; edge positions and oxidation states from K-edge XAS; EXAFS simulations and fit parameters; FT-EXAFS of the CuHCF cathode; and EDS spectra and elemental compositions of two carbon "blank" cathodes (PDF)

\section{AUTHOR INFORMATION}

\section{Corresponding Authors}

Mikaela Görlin - Department of Chemistry-Ångström Laboratory, Uppsala University, SE-75121 Uppsala, Sweden; Present Address: Department of Mechanical Engineering, Research Laboratory of Electronics, Massachusetts Institute of Technology, Cambridge, Massachusetts 02139, United States; 10 orcid.org/0000-0003-4472955X; Email: mikaela.gorlin@kemi.uu.se

Mario Valvo - Department of Chemistry-Ångström Laboratory, Uppsala University, SE-75121 Uppsala, Sweden; 이이.org/0000-0002-0069-8707;

Email: mario.valvo@kemi.uu.se

\section{Authors}

Dickson O. Ojwang - Department of Chemistry-Ångström Laboratory, Uppsala University, SE-75121 Uppsala, Sweden; (1) orcid.org/0000-0001-9304-8975

Ming-Tao Lee - Department of Chemistry-Ångström Laboratory, Uppsala University, SE-75121 Uppsala, Sweden; (1) orcid.org/0000-0002-1029-2110

Viktor Renman - Department of Materials Science and Engineering, Norwegian University of Science and Technology, NO-7491 Trondheim, Norway; (1) orcid.org/ 0000-0001-8739-4054

Cheuk-Wai Tai - Department of Materials and Environmental Chemistry, Stockholm University, SE-106 91 Stockholm, Sweden; (1) orcid.org/0000-0001-7286-1211

Complete contact information is available at: https://pubs.acs.org/10.1021/acsami.1c19167

\section{Author Contributions}

M.G. carried out most of the electrochemical characterization including XRD, XAS, XPS, SEM-EDS, and ICP-OES analyses, performed the data evaluation, prepared the figures, and wrote the manuscript. D.O. carried out ICP-OES, XRD, Raman spectroscopy, and synthesis and contributed to data evaluation. M-T.L. assisted with XPS measurements and contributed to XPS data analysis and evaluation. C.-W.T. performed HAADFSTEM and EDS mapping and contributed to data evaluation. V.R. contributed to synthesis and data evaluation. M.V. performed Raman spectroscopy and contributed to the data analysis and to the overall experimental design, providing hands-on expertise and guidance throughout the project. All co-authors have seen, discussed, and approved the content of this manuscript.

\section{Notes}

The authors declare no competing financial interest.

\section{ACKNOWLEDGMENTS}

M.V. gratefully acknowledges the Åforsk Foundation for funding this project (grant nos. 18-317 and 19-594) and the support by the Swedish Energy Agency via Batterifondsprogrammet (grant no. 2017-013531). We also thank the strategic research network StandUp for Energy. D.O. is grateful to the Swedish Energy Agency. Part of this work was performed at 
the Electron Microscopy Centre, supported by the Department of Materials and Environmental Chemistry and Faculty of Science at Stockholm University, Sweden. C.-W.T. is also supported by the Swedish Foundation for Strategic Research (SSF) (project no. ITM17-0301). We also thank Prof. Holger Dau for support with XAS at the KMC-3 beamline at BESSY II, Helmholtz Zentrum Berlin (HZB), with support from the Helmholtz Association (VH-NG-1140), the Bundesministerium für Bildung und Forschung (IN-SITU-XAS, 05K16KE2), and the Deutsche Forschungsgemeinschaft (Cluster of Excellence UniCat, EXC 314-2). We also thank Dr. Petko Chernev and Dr. Ivo Zizak for valuable support at the KMC-3 beamline.

\section{REFERENCES}

(1) Yang, Z.; Zhang, J.; Kintner-Meyer, M. C. W.; Lu, X.; Choi, D.; Lemmon, J. P.; Liu, J. Electrochemical Energy Storage for Green Grid. Chem. Rev. 2011, 111, 3577-3613.

(2) Dunn, B.; Kamath, H.; Tarascon, J.-M. Electrical Energy Storage for the Grid : A Battery of Choices. Science 2011, 334, 928-936.

(3) Olivetti, E. A.; Ceder, G.; Gaustad, G. G.; Fu, X. Lithium-Ion Battery Supply Chain Considerations: Analysis of Potential Bottlenecks in Critical Metals. Joule 2017, 1, 229-243.

(4) Valvo, M.; Liivat, A.; Eriksson, H.; Tai, C.-W.; Edström, K. IronBased Electrodes Meet Water-Based Preparation, Fluorine-Free Electrolyte and Binder: A Chance for More Sustainable Lithium-Ion Batteries? ChemSusChem 2017, 10, 2431-2448.

(5) Muñoz-Márquez, M. Á.; Saurel, D.; Gómez-Cámer, J. L.; CasasCabanas, M.; Castillo-Martínez, E.; Rojo, T. Na-Ion Batteries for Large Scale Applications: A Review on Anode Materials and Solid Electrolyte Interphase Formation. Adv. Energy Mater. 2017, 7, 1700463.

(6) Konarov, A.; Voronina, N.; Jo, J. H.; Bakenov, Z.; Sun, Y.-K.; Myung, S.-T. Present and Future Perspective on Electrode Materials for Rechargeable Zinc-Ion Batteries. ACS Energy Lett. 2018, 3, 26202640.

(7) Pan, H.; Shao, Y.; Yan, P.; Cheng, Y.; Han, K. S.; Nie, Z.; Wang, C.; Yang, J.; Li, X.; Bhattacharya, P.; Mueller, K. T.; Liu, J. Reversible Aqueous Zinc/Manganese Oxide Energy Storage from Conversion Reactions. Nat. Energy 2016, 1, 16039.

(8) Zeng, X.; Hao, J.; Wang, Z.; Mao, J.; Guo, Z. Recent Progress and Perspectives on Aqueous Zn-Based Rechargeable Batteries with Mild Aqueous Electrolytes. Energy Storage Mater. 2019, 20, 410-437.

(9) Yang, D.; Tan, H.; Rui, X.; Yu, Y. Electrode Materials for Rechargeable Zinc-Ion and Zinc-Air Batteries: Current Status and Future Perspectives. Electrochem. Energy Rev. 2019, 2, 395-427.

(10) Shin, J.; Choi, J. W. Opportunities and Reality of Aqueous Rechargeable Batteries. Adv. Energy Mater. 2020, 10, 2001386.

(11) Zampardi, G.; La Mantia, F. Prussian Blue Analogues as Aqueous Zn-Ion Batteries Electrodes: Current Challenges and Future Perspectives. Curr. Opin. Electrochem. 2020, 21, 84-92.

(12) Chen, Z.; Wang, P.; Ji, Z.; Wang, H.; Liu, J.; Wang, J.; Hu, M.; Huang, Y. High-Voltage Flexible Aqueous Zn-Ion Battery with Extremely Low Dropout Voltage and Super-Flat Platform. Nano-Micro Lett. 2020, 12, 75.

(13) Ojwang, D. O.; Grins, J.; Wardecki, D.; Valvo, M.; Renman, V.; Häggström, L.; Ericsson, T.; Gustafsson, T.; Mahmoud, A.; Hermann, R. P.; Svensson, G. Structure Characterization and Properties of KContaining Copper Hexacyanoferrate. Inorg. Chem. 2016, 55, 59245934.

(14) Wessells, C. D.; Peddada, S. V.; McDowell, M. T.; Huggins, R. A.; Cui, Y. The Effect of Insertion Species on Nanostructured Open Framework Hexacyanoferrate Battery Electrodes. J. Electrochem. Soc. 2011, 159, A98-A103.

(15) Chen, S.-M. Preparation, Characterization, and Electrocatalytic Oxidation Properties of Iron, Cobalt, Nickel, and Indium Hexacyanoferrate. Electroanal. Chem. 2002, 521, 29-52.
(16) Mizuno, Y.; Okubo, M.; Hosono, E.; Kudo, T.; Oh-ishi, K.; Okazawa, A.; Kojima, N.; Kurono, R.; Nishimura, S.-i.; Yamada, A. Electrochemical $\mathrm{Mg} 2+$ Intercalation into a Bimetallic CuFe Prussian Blue Analog in Aqueous Electrolytes. J. Mater. Chem. A 2013, 1, 13055-13059.

(17) Jia, Z.; Wang, B.; Wang, Y. Copper Hexacyanoferrate with a Well-Defined Open Framework as a Positive Electrode for Aqueous Zinc Ion Batteries. Mater. Chem. Phys. 2015, 149-150, 601-606.

(18) Trócoli, R.; La Mantia, F. An Aqueous Zinc-Ion Battery Based on Copper Hexacyanoferrate. ChemSusChem 2015, 8, 481-485.

(19) Zhang, L.; Chen, L.; Zhou, X.; Liu, Z. Towards High-Voltage Aqueous Metal-Ion Batteries Beyond 1.5 V: The Zinc/Zinc Hexacyanoferrate System. Adv. Energy Mater. 2015, 5, 1400930.

(20) Deng, C.; Wang, D. W. Functional Electrocatalysts Derived from Prussian Blue and Its Analogues for Metal-Air Batteries: Progress and Prospects. Batteries Supercaps 2019, 2, 290-310.

(21) Wang, L.-P.; Wang, P.-F.; Wang, T.-S.; Yin, Y.-X.; Guo, Y.-G.; Wang, C.-R. Prussian Blue Nanocubes as Cathode Materials for Aqueous Na-Zn Hybrid Batteries. J. Power Sources 2017, 355, 18-22.

(22) Wang, R. Y.; Shyam, B.; Stone, K. H.; Weker, J. N.; Pasta, M.; Lee, H.-W.; Toney, M. F.; Cui, Y. Reversible Multivalent (Monovalent, Divalent, Trivalent) Ion Insertion in Open Framework Materials. Adv. Energy Mater. 2015, 5, 1401869.

(23) Wang, R. Y.; Wessells, C. D.; Huggins, R. A.; Cui, Y. Highly Reversible Open Framework Nanoscale Electrodes for Divalent Ion Batteries. Nano Lett. 2013, 13, 5748-5752.

(24) Pasta, M.; Wessells, C. D.; Huggins, R. A.; Cui, Y. A High-Rate and Long Cycle Life Aqueous Electrolyte Battery for Grid-Scale Energy Storage. Nat. Commun. 2012, 3, 1149.

(25) Wessells, C. D.; Huggins, R. A.; Cui, Y. Copper Hexacyanoferrate Battery Electrodes with Long Cycle Life and High Power. Nat. Commun. 2011, 2, 550.

(26) Jiang, P.; Shao, H.; Chen, L.; Feng, J.; Liu, Z. Ion-Selective Copper Hexacyanoferrate with an Open-Framework Structure Enables High-Voltage Aqueous Mixed-Ion Batteries. J. Mater. Chem. A 2017, 5, 16740-16747.

(27) Wardecki, D.; Ojwang, D. O.; Grins, J.; Svensson, G. Neutron Diffraction and EXAFS Studies of $\mathrm{K} 2 \mathrm{x} / 3 \mathrm{Cu}[\mathrm{Fe}(\mathrm{CN}) 6] 2 / 3 \cdot \mathrm{nH} 2 \mathrm{O}$. Cryst. Growth Des. 2017, 17, 1285-1292.

(28) Kasiri, G.; Glenneberg, J.; Kun, R.; Zampardi, G.; La Mantia, F. Microstructural Changes of Prussian Blue Derivatives during Cycling in Zinc-Containing Electrolytes. ChemElectroChem 2020, 7, 33013310.

(29) Trócoli, R.; Kasiri, G.; La Mantia, F. Phase Transformation of Copper Hexacyanoferrate $(\mathrm{KCuFe}(\mathrm{CN}) 6)$ during Zinc Insertion: Effect of Co-Ion Intercalation. J. Power Sources 2018, 400, 167-171.

(30) Lim, J.; Kasiri, G.; Sahu, R.; Schweinar, K.; Hengge, K.; Raabe, D.; La Mantia, F.; Scheu, C. Irreversible Structural Changes of Copper Hexacyanoferrate Used as a Cathode in Zn-Ion Batteries. Chem.-Eur. J. 2020, 26, 4917-4922.

(31) Renman, V.; Ojwang, D. O.; Valvo, M.; Gómez, C. P.; Gustafsson, T.; Svensson, G. Structural-Electrochemical Relations in the Aqueous Copper Hexacyanoferrate-Zinc System Examined by Synchrotron X-Ray Diffraction. J. Power Sources 2017, 369, 146-153.

(32) Kasiri, G.; Trócoli, R.; Bani Hashemi, A.; La Mantia, F. An Electrochemical Investigation of the Aging of Copper Hexacyanoferrate during the Operation in Zinc-Ion Batteries. Electrochim. Acta 2016, 222, 74-83.

(33) Gupta, T.; Kim, A.; Phadke, S.; Biswas, S.; Luong, T.; Hertzberg, B. J.; Chamoun, M.; Evans-Lutterodt, K.; Steingart, D. A. Improving the Cycle Life of a High-Rate, High-Potential Aqueous Dual-Ion Battery Using Hyper-Dendritic Zinc and Copper Hexacyanoferrate. J. Power Sources 2016, 305, 22-29.

(34) Kasiri, G.; Glenneberg, J.; Bani Hashemi, A.; Kun, R.; La Mantia, F. Mixed Copper-Zinc Hexacyanoferrates as Cathode Materials for Aqueous Zinc-Ion Batteries. Energy Storage Mater. 2019, 19, 360.

(35) Mullaliu, A.; Conti, P.; Aquilanti, G.; Plaisier, R. J.; Stievano, L.; Giorgetti, M. Operando XAFS and XRD Study of a Prussian Blue 
Analogue Cathode Material: Iron Hexacyanocobaltate. Condens. Matter 2018, 3, 36.

(36) Mullaliu, A.; Aquilanti, G.; Conti, P.; Plaisier, J. R.; Fehse, M.; Stievano, L.; Giorgetti, M. Copper Electroactivity in Prussian BlueBased Cathode Disclosed by Operando XAS. J. Phys. Chem. C 2018, 122, 15868-15877.

(37) Makowski, O.; Stroka, J.; Kulesza, P. J.; Malik, M. A.; Galus, Z. Electrochemical Identity of Copper Hexacyanoferrate in the SolidState: Evidence for the Presence and Redox Activity of Both Iron and Copper Ionic Sites. J. Electroanal. Chem. 2002, 532, 157-164.

(38) Shankaran, D. R.; Narayanan, S. S. Characterization and Application of an Electrode Modified by Mechanically Immobilized Copper Hexacyanoferrate. Fresenius. J. Anal. Chem. 1999, 364, 686689.

(39) Giorgetti, M.; Tonelli, D.; Berrettoni, M.; Aquilanti, G.; Minicucci, M. Copper Hexacyanoferrate Modified Electrodes for Hydrogen Peroxide Detection as Studied by X-Ray Absorption Spectroscopy. J. Solid State Electrochem. 2014, 18, 965-973.

(40) Naveed, A.; Yang, H.; Yang, J.; Nuli, Y.; Wang, J. Highly Reversible and Rechargeable Safe Zn Batteries Based on a Triethyl Phosphate Electrolyte. Angew. Chem., Int. Ed. 2019, 58, 2760-2764.

(41) Chamoun, M.; Brant, W. R.; Tai, C.-W.; Karlsson, G.; Noréus, D. Rechargeability of Aqueous Sulfate $\mathrm{Zn} / \mathrm{MnO} 2$ Batteries Enhanced by Accessible Mn2+ Ions. Energy Storage Mater. 2018, 15, 351-360.

(42) Top, A.; Çetinkaya, H. Zinc Oxide and Zinc Hydroxide Formation via Aqueous Precipitation: Effect of the Preparation Route and Lysozyme Addition. Mater. Chem. Phys. 2015, 167, 77-87.

(43) Seiler, S.; Halbig, C. E.; Grote, F.; Rietsch, P.; Börrnert, F.; Kaiser, U.; Meyer, B.; Eigler, S. Effect of Friction on Oxidative Graphite Intercalation and High-Quality Graphene Formation. Nat. Commun. 2018, 9, 836.

(44) Qi, X.; Blizanac, B.; DuPasquier, A.; Meister, P.; Placke, T.; Oljaca, M.; Li, J.; Winter, M. Investigation of PF6- and TFSI- Anion Intercalation into Graphitized Carbon Blacks and Its Influence on High Voltage Lithium Ion Batteries. Phys. Chem. Chem. Phys. 2014, 16, 25306-25313.

(45) Ferrari, A. C. Raman Spectroscopy of Graphene and Graphite: Disorder, Electron-Phonon Coupling, Doping and Nonadiabatic Effects. Solid State Commun. 2007, 143, 47-57.

(46) Blume, R.; Rosenthal, D.; Tessonnier, J.-P.; Li, H.; KnopGericke, A.; Schlögl, R. Characterizing Graphitic Carbon with X-Ray Photoelectron Spectroscopy: A Step-by-Step Approach. ChemCatChem 2015, 7, 2871-2881.

(47) Kotronia, A.; Asfaw, H. D.; Tai, C.-W.; Hahlin, M.; Brandell, D.; Edström, K. Nature of the Cathode-Electrolyte Interface in Highly Concentrated Electrolytes Used in Graphite Dual-Ion Batteries. ACS Appl. Mater. Interfaces 2021, 13, 3867-3880.

(48) Moraes, A.; Assumpção, M. H. M. T.; Simões, F. C.; Antonin, V. S.; Lanza, M. R. V.; Hammer, P.; Santos, M. C. Surface and Catalytical Effects on Treated Carbon Materials for Hydrogen Peroxide Electrogeneration. Electrocatalysis 2016, 7, 60-69.

(49) Wang, G.; Feng, C. Electrochemical Polymerization of Hydroquinone on Graphite Felt as a Pseudocapacitive Material for Application in a Microbial Fuel Cell. Polymers 2017, 9, 220.

(50) Wang, N.; Ma, W.; Du, Y.; Ren, Z.; Han, B.; Zhang, L.; Sun, B.; $\mathrm{Xu}$, P.; Han, X. Prussian Blue Microcrystals with Morphology Evolution as a High-Performance Photo-Fenton Catalyst for Degradation of Organic Pollutants. ACS Appl. Mater. Interfaces 2019, 11, 1174-1184.

(51) Lin, K.-Y. A.; Chen, B.-J. Prussian Blue Analogue Derived Magnetic Carbon/Cobalt/Iron Nanocomposite as an Efficient and Recyclable Catalyst for Activation of Peroxymonosulfate. Chemosphere 2017, 166, 146-156.

(52) Blyth, R. I. R.; Buqa, H.; Netzer, F. P.; Ramsey, M. G.; Besenhard, J. O.; Golob, P.; Winter, M. XPS Studies of Graphite Electrode Materials for Lithium Ion Batteries. Appl. Surf. Sci. 2000, 167, 99-106.
(53) Castorina, E.; Ingall, E. D.; Morton, P. L.; Tavakoli, D. A.; Lai, B. Zinc K-Edge XANES Spectroscopy of Mineral and Organic Standards. J. Synchrotron Radiat. 2019, 26, 1302-1309.

(54) Zhang, Z.; Huang, J.; Xia, H.; Dai, Q.; Gu, Y.; Lao, Y.; Wang, X. Chlorinated Volatile Organic Compound Oxidation over SO42-/ Fe2O3 Catalysts. J. Catal. 2018, 360, 277-289.

(55) Hernández, G.; Naylor, A. J.; Chien, Y.-C.; Brandell, D.; Mindemark, J.; Edström, K. Elimination of Fluorination: The Influence of Fluorine-Free Electrolytes on the Performance of LiNi1/3Mn1/3Co1/3O2/Silicon-Graphite Li-Ion Battery Cells. ACS Sustain. Chem. Eng. 2020, 8, 10041-10052.

(56) Zhang, Y.; Dong, K.; Liu, Z.; Wang, H.; Ma, S.; Zhang, A.; Li, M.; Yu, L.; Li, Y. Sulfurized Hematite for Photo-Fenton Catalysis. Prog. Nat. Sci.: Mater. Int. 2017, 27, 443-451.

(57) Cano, A.; Avila, Y.; Avila, M.; Reguera, E. Structural Information Contained in the XPS Spectra of Nd10 Metal Cyanides. J. Solid State Chem. 2019, 276, 339-344.

(58) Cano, A.; Rodríguez-Hernández, J.; Reguera, L.; RodríguezCastellón, E.; Reguera, E. On the Scope of XPS as Sensor in Coordination Chemistry of Transition Metal Hexacyanometallates. Eur. J. Inorg. Chem. 2019, 2019, 1724-1732.

(59) Tian, C.; Kan, E.; Lee, C.; Whangbo, M.-H. $\pi$-Back-Donation Effect of the Cyanide Ligands on the Electron Correlation and Charge Transfer in Prussian Blue $\mathrm{RbMn}[\mathrm{Fe}(\mathrm{CN}) 6]$. Inorg. Chem. 2010, 49, 3086-3088.

(60) Pan, G.; Chen, J.; Ge, K.; Yang, L.; Li, F.; Wang, Z.; Shi, S.; Yang, X.; Zhou, Z.; Tang, A.; Liu, W.; Sun, Y. Zn(O,S)-Based Electron-Selective Contacts with Tunable Band Structure for Silicon Heterojunction Solar Cells. J. Mater. Chem. C 2019, 7, 4449-4458.

(61) Lee, M. T.; Liu, H.; Brandell, D. The Surface Chemistry of Thin Lithium Metal Electrodes in Lithium-Sulfur Cells. Batteries Supercaps 2020, 3, 1370-1376.

(62) Baker, M. L.; Mara, M. W.; Yan, J. J.; Hodgson, K. O.; Hedman, B.; Solomon, E. I. K- and L-Edge X-Ray Absorption Spectroscopy (XAS) and Resonant Inelastic X-Ray Scattering (RIXS) Determination of Differential Orbital Covalency (DOC) of Transition Metal Sites. Coord. Chem. Rev. 2017, 345, 182-208.

(63) McCubbin Stepanic, O.; Ward, J.; Penner-Hahn, J. E.; Deb, A.; Bergmann, U.; DeBeer, S. Probing a Silent Metal: A Combined X-Ray Absorption and Emission Spectroscopic Study of Biologically Relevant Zinc Complexes. Inorg. Chem. 2020, 59, 13551-13560.

(64) Jacquamet, L.; Aberdam, D.; Adrait, A.; Hazemann, J.-L.; Latour, J.-M.; Michaud-Soret, I. X-Ray Absorption Spectroscopy of a New Zinc Site in the Fur Protein from Escherichia Coli. Biochemistry 1998, 37, 2564-2571.

(65) Mullaliu, A.; Aquilanti, G.; Stievano, L.; Conti, P.; Plaisier, J. R.; Cristol, S.; Giorgetti, M. Beyond the Oxygen Redox Strategy in Designing Cathode Material for Batteries: Dynamics of a Prussian Blue-like Cathode Revealed by Operando X-Ray Diffraction and XRay Absorption Fine Structure and by a Theoretical Approach. J. Phys. Chem. C 2019, 123, 8588-8598.

(66) Giorgetti, M.; Guadagnini, L.; Tonelli, D.; Minicucci, M.; Aquilanti, G. Structural Characterization of Electrodeposited Copper Hexacyanoferrate Films by Using a Spectroscopic Multi-Technique Approach. Phys. Chem. Chem. Phys. 2012, 14, 5527-5537.

(67) Yang, Q.; Mo, F.; Liu, Z.; Ma, L.; Li, X.; Fang, D.; Chen, S.; Zhang, S.; Zhi, C. Activating C-Coordinated Iron of Iron Hexacyanoferrate for Zn Hybrid-Ion Batteries with 10 000-Cycle Lifespan and Superior Rate Capability. Adv. Mater. 2019, 31, 1901521.

(68) Phadke, S.; Mysyk, R.; Anouti, M. Effect of Cation (Li+, Na+, $\mathrm{K}+, \mathrm{Rb}+, \mathrm{Cs}+)$ in Aqueous Electrolyte on the Electrochemical Redox of Prussian Blue Analogue (PBA) Cathodes. J. Energy Chem. 2020, 40, $31-38$.

(69) Agrisuelas, J.; García-Jareño, J. J.; Gimenez-Romero, D.; Vicente, F. Insights on the Mechanism of Insoluble-to-Soluble Prussian Blue Transformation. J. Electrochem. Soc. 2009, 156, P149. 